WIENER SLAVISTISCHES JAHRBUCH, Band 52/2006, 63-84

(C) 2007 by Österreichische Akademie der Wissenschaften, Wien

ROMAN KRIVKO

\title{
Rekonstruktion der griechischen Akrostichis im Kanon auf das hl. Mandylion: Zur Bedeutung altkirchenslavischer Übersetzungen für die byzantinische Überlieferung ${ }^{1}$
}

Die altkirchenslavische (aksl.) übersetzte Hymnographie spiegelt die Textgeschichte ihrer byzantinischen Vorlagen wider. Von diesem Gesichtspunkt wurden aber altkirchenslavische Übersetzungen noch kaum erforscht, obwohl sie Angaben zu griechischen Originalen enthalten können, die aus der verfügbaren byzantinischen Überlieferung nicht bekannt sind. So ist es I. Dobrev gelungen, auf Grund einer Rückübersetzung vom Altkirchenslavischen ins Griechische zu beweisen, dass der Kanon ${ }^{2}$ zu Ehren des hl. Johannes von Rila kein altbulgarischer Text, sondern eine mittelbulgarische Übersetzung eines unbekannten byzantinischen Originals darstellt, da die ersten Buchstaben der wiederhergestellten Incipita der griechischen Troparia in Akrostichis den Namen des byzantinischen Hymnographen Georgios Skylitzes (12. Jh.) ergeben (Добрев 2002). Auf diese Weise wurden Spuren der griechischen Akrostichis auch im Kanon auf den hl. Kyrill den Philosophen rekonstruiert (Темчин 2007). Textgeschichtliche Befunde der altkirchenslavischen Gottesdienste auf den hl. Ioakim von Osogov ließen Subotin-Golubović zum Schluss kommen, dass diese Gottesdienste von einem nicht erhaltenen byzantinischen Original

${ }^{1}$ Die Arbeit wurde von dem Österreichischen Fonds zur Förderung der wissenschaftlichen Forschung (FWF Projekt Nr. M819-G03) gefördert. Es ist mir eine angenehme Pflicht, Mag. Johannes Grossmann (Wien, München) sowie Prof. Dr. Heinz Miklas (Wien) für die sprachliche Revision der Abhandlung herzlichst zu danken. Für Bemerkungen und Diskussion bedanke ich mich bei Dr. Kirill Maksimovič (Moskau) und Prof. Dr. Vadim Krys'ko (Moskau)

2 Der Kanon ist ,,nach dem Kontakion die zweite u. letzte Hochform der byz. Kirchendichtung. Die Grundeinheit des K.s ... ist die aus ... Troparien bestehende Ode“ (Onasch 1981: 179; s. auch: Plank 1996). Troparia sind die Strophen, die nach einer das rhythmische

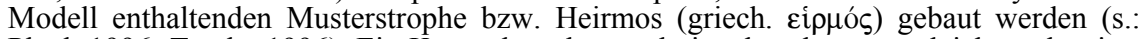
Plank 1996; Totzke 1996). Ein Kanon besteht aus drei, acht oder neun gleich strukturierten Oden. 
stammen (Суботин-Голубовић 1992). Die sprachliche Analyse des Ilja-Buchs (Il'ina kniga) lässt den Einfluss byzantinischer Originale bei mehreren altkirchenslavischen Texten erkennen, so auch beim Kanon auf den hl. Philosophen Kyrill, für den keine griechische Vorlage entdeckt wurde (Крысько 2005, 2005a). Die Bedeutung der altkirchenslavischen Hymnographie für die Geschichte und Rekonstruktion ihrer byzantinischen Quellen kann auch am Beispiel eines Kanons auf die Übertragung

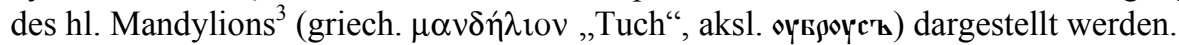

Die in der russisch-orthodoxen Kirche heutzutage gebräuchlichen Gottesdienstmenäen für den Monat August enthalten einen Kanon auf die Übertragung des hl. Mandylions ${ }^{4}$. Dessen griechisches Original wurde vor nicht langer Zeit von P. Peter Plank und Carolina Lutzka identifiziert und publiziert (Plank - Lutzka 2006: 10591062; 1112-1115). Das Incipit des im vorliegenden Aufsatz analysierten Kanons ist

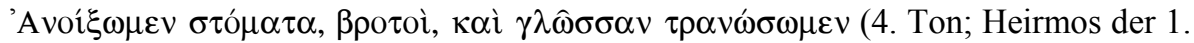

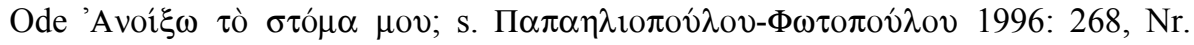
839; AHG XII: 468). Zum Unterschied von der in den byzantinischen Handschriften überlieferten Fassung des Kanons enthält die kirchenslavische Übersetzung Theoto$\mathrm{kia}^{5}$, die in der griechischen Version fehlen. Obwohl die byzantinischen Originale der Theotokia nicht identifiziert wurden, stellten Plank und Lutzka zu Recht fest: „Die Anfangsbuchstaben der ... Theotokia ergeben offenbar die Akrostichis

${ }^{3}$ Die deutsche Form Mandylion folgt griech. $\mu \alpha v \delta$ v́ $\lambda$ iov, das von lateinisch mantelium „Tuch" herzuleiten ist. Griechisch $\mu \alpha v \delta v ́ \lambda$ ıov stellt also das Ergebnis des mittelgriechischen Itazismus dar, weshalb man als ursprüngliche Form des griechischen Lehnwortes

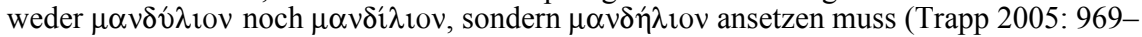

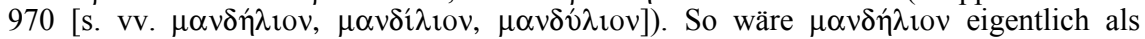
**Mandilion oder **Mandelion wiederzugeben; vgl. dazu das etymologisch verwandte Mantel.

${ }^{4}$ Nach den byzantinischen hagiographischen und historischen Quellen enthielt das Mandy-

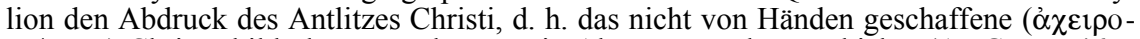

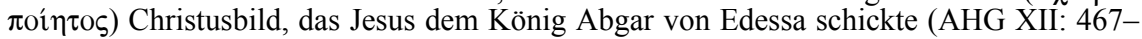
469 [Bibliographie]); ,die Erweiterung der Abgarlegende dürfte ebenfalls im 6. Jahrhundert entstanden sein" (Beck 1959: 297; vgl. BHG 793-796m, 1702-1705; Warland 1993). Das hl. Mandylion wurde 944 von Edessa nach Konstantinopel übertragen (Beck 1959: 297, 551); diesem Fest wurden folgende Kanones gewidmet: 1) Inc. $\Sigma \omega \mu \alpha \tau 1 \kappa \hat{\omega} \varsigma \mu$ но-

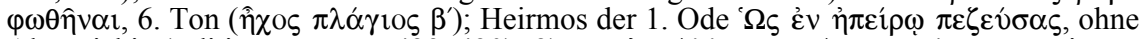

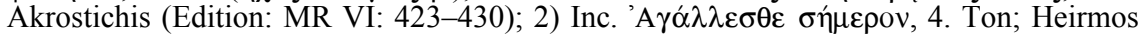

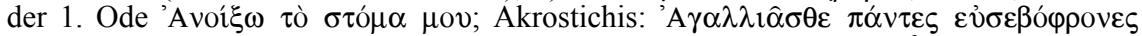

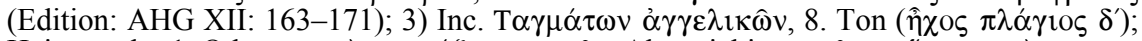

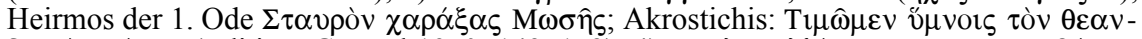

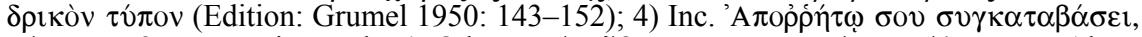

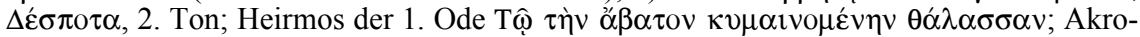

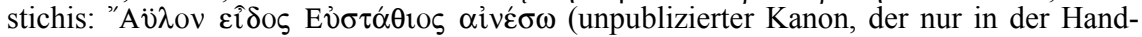

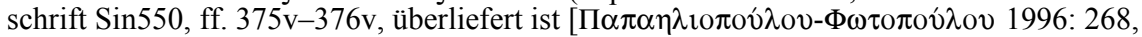

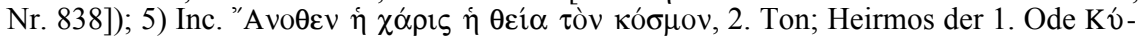

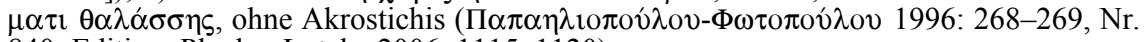
840; Edition: Plank - Lutzka 2006: 1115-1120).

5 Das Theotokion ist jene Strophe in jeder Ode des Kanons, die besonders der Verehrung der Gottesmutter und der Menschwerdung Christi gewidmet ist. 


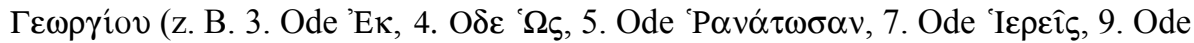
"Y భоs usw.)" (Plank - Lutzka 2006: 1059). Es ist zu betonen, dass sich dieselbe Übersetzung des Kanons in altkirchenslavischen Gottesdienstmenäen findet, die von einer Version aus der Mitte des 11. Jh. abstammen. Diese Tatsache ist von großer Bedeutung nicht nur für den Kanon auf die Übertragung des hl. Mandylions, sondern auch für alle eine Akrostichis mit dem Namen $\Gamma \varepsilon \omega \rho \gamma$ fíov in den Theotokia enthaltenden byzantinischen Kanones.

Die ältesten Quellen der altkirchenslavischen Übersetzung des oben genannten

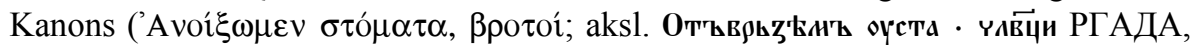
ф. 381 [Тип.], Nr. 125, f. 44v.) sind altrussische Handschriften Novgoroder Provenienz:

РГАДА, ф. 381 [Тип.], Nr. 125, ff. 44v-48; 11.-12. Jh. (im Folgenden: Т) (Каталог 1984: 83-84);

ГИМ, Син. 168, ff. 97-100; 12. Jh. (im Folgenden: S) (Каталог 1984: 128$129)^{7}$.

Diese Übersetzung war auch den Südslaven bekannt. Ihre ältesten Textzeugen sind zwei altserbische Handschriften:

НБС, Деч. 32, Ende 13. - Anfang 14. Jh. (im Folgenden: D) (Богдановић 1982: 56; Гроздановић-Пајић - Станковић 1995: 12);

НБС, Рс. 647, 14. Jh. (im Folgenden: ВМ) („Братков минеј“) (Богдановић 1982: 49-50; Штављанин-Ђорђевић et al. 1986: 340-345).

Das byzantinische Original der altkirchenslavischen Übersetzung ist nur in zwei Handschriften erhalten (П $\alpha \pi \alpha \eta \lambda$ ıо

Sinai, Sin. gr. 632, ff. 93v-98v, 12. Jh. (im Folgenden: Sin632) (Gardthausen 1886: $146^{8}$; Clark 1952: 9);

ÖNB, Vind. theol. gr. 33, f. 166r-v, 13. Jh. (im Folgenden: W33) (Hunger - Kresten 1976: 57-64).

Für die Textgeschichte des byzantinischen Kanons ist es wichtig, dass gemäß der auf den studitischen Typika gegründeten liturgischen Tradition die Übertragung des hl. Mandylions am gleichen Tag (16. August) wie das Gedächtnis des Martyrers Diomidos zu begehen war (Сергій 1901: 247-248) und deshalb am 16. August zwei Kanones zu singen waren: auf den hl. Diomidos und auf die Übertragung des hl.

${ }^{6}$ Die Handschrift gehört zu einem Komplex von Gottesdienstmenäen aus dem Russischen Staatlichen Archiv alter Akten (РГАДА), Moskau: Тип. Nrr. 99, 103, 110, 121, 125. Die Reihe wird ins 11.-12. Jh. datiert (Князевская et al. 1988: 41-49 [Bibliographie]). Auf Grund mancher phonologischer und orthographischer Innovationen wurde kürzlich eine spätere Datierung (12. Jh.) vorgeschlagen (Кривко 2005).

7 Die Handschrift gehört zur Serie von Gottesdienstmenäen aus der Sammlung des Staatlichen Historischen Museums (ГИМ), Moskau: Син, Nrr. 159, 160, 161, 162, 163, 164, 165, 166, 167, 168 (Каталог 1984: 119-129).

8 Gardthausen datiert die Handschrift ins 10.-11. Jh. Im vorliegenden Aufsatz wird die Datierung von Clark 1952 übernommen. 
Mandylions. Mehrere Kanones konnten in der Akoluthie des Tages kombiniert werden, so dass nur ein aus zwei oder mehreren Kanones bestehender Text in einer Handschrift erhalten sein kann. In W33 besteht jede der acht Oden des derart kombinierten Kanons aus einem gemeinsamen Heirmos, auf den zwei Troparia aus dem Kanon auf den hl. Diomidos und danach zwei Troparia des Kanons auf die Übertragung des hl. Mandylions folgen ${ }^{9}$. Die alphabetische Akrostichis des Kanons auf die Übertragung des hl. Mandylions ist in dieser Version nicht vollständig, weil das erste Troparion jeder Ode des Kanons durch zwei Troparia des Kanons auf den hl. Diomidos ersetzt worden war und daher der erste, vierte, sechste usw. Buchstabe der Akrostichis ausgefallen ist. Da der Kanon auf die Übertragung des hl. Mandylions in W33 mit einem anderen Kanon kombiniert wurde und deshalb in gekürzter Version erhalten ist, wurde er im Katalog der griechischen Handschriften der ÖNB nicht

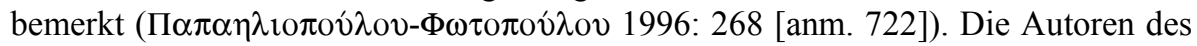
Katalogs stellten irrtümlich fest, dass in der Handschrift nur der Kanon auf den hl. Diomidos „mit starken Textabweichungen“ von der Edition (MR VI 424-431) erhalten sei (Hunger - Kresten 1976: 62) ${ }^{10}$.

Der Kanon auf die Übertragung des hl. Mandylions ist in der kombinierten Version nicht nur in W33 erhalten, sondern auch in der zweiten Handschrift, Sin632. In dieser Quelle besteht jede Ode des kombinierten Kanons aus dem gemeinsamen Heirmos, auf den alle gewöhnlichen Troparia des Kanons auf die Übertragung des hl. Mandylions (ohne Theotokia) und anschließend alle gewöhnlichen Troparia des Kanons auf den hl. Domidos folgen. Am Ende jeder Ode findet sich das zum Kanon auf den hl. Diomidos gehörende Theotokion. Die alphabetische Akrostichis des Kanons auf die Übertragung des hl. Mandylions ist in dieser Version vollständig, aber die ursprünglichen Theotokia fehlen, wie in der Handschrift W33. Die Ursache des Ausfalls der Theotokia in beiden Kanones war ihre Kombination mit dem Kanon auf den hl. Diomidos ${ }^{11}$.

In der ältesten kirchenslavischen Überlieferung wird der Kanon auf die Übertragung des hl. Mandylions mit dem zweiten Kanon des Tages nicht kombiniert und ist deshalb in beiden Handschriften vollständig erhalten (freilich ohne Akrostichis, die in der altkirchenslavischen Überlieferung fast nie übersetzt wurde [Hannick

${ }^{9}$ Über die Kombination von Kanones im Gottesdienst eines Tages s. Суботин-Голубовић 1987.

10 Nach der Beschreibung handelt es sich nur um das Gedächtnis des hl. Diomidos (Hunger - Kresten 1976: 62), obwohl der Gottesdienst des Tages mit den Stichera auf die Übertragung des hl. Mandylions anfängt (W33, f. 166).

11 Über Ausfall oder Ersatz der ursprünglichen Theotokia in kombinierten Versionen von Kanones s. Follieri 1964: 318; AHG IV: 853; vgl. auch den Ausfall der Theotokia mit dem Namen des Autors ( $\Gamma \varepsilon \dot{\rho} \rho \gamma(0)$ ) im Kanon auf den hl. Artemonos, der sich auch in der Handschrift Crypt. $\Delta$. $\alpha$. XVII (Rocchi 1883: 318-319) findet: „L'autore del canone è

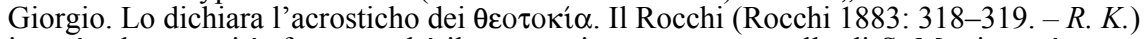
ignorà tale paternità, forse perché il canone, innestato con quello di S. Martiono, è stato, come talvolta accade, privato dei $\theta \varepsilon 0 \tau$ oкí $\alpha$ " (AHG VIII: 185). 
1973]) ${ }^{12}$. Die altkirchenslavische Version ist aber vollständiger als die bekannten byzantinischen Texte, weil, wie gesagt (Plank - Lutzka 2006: 1059), es in jeder Ode des übersetzten Kanons die Theotokia gibt, die in beiden byzantinischen Handschriften, W33 und Sin632, fehlen. Obwohl die Theotokia eines Kanons aus einem anderen Kanon desselben Tons und der gleichen rhythmischen Struktur übernommen werden konnten (Follieri 1964: 316-317) ${ }^{13}$, stimmen in unserem Fall die Theotokia inhaltlich mit der Thematik des Kanons überein und gehören folglich zu seiner ursprünglichen Fassung ${ }^{14}$.

Obwohl byzantinische Originale der altkirchenslavischen Theotokia nicht bekannt sind, können ihre Incipita auf Grund der altkirchenslavischen Übersetzung wiederhergestellt werden.

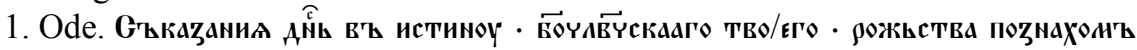

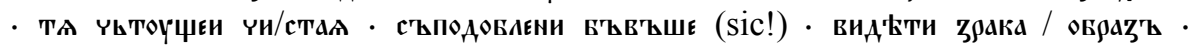
нероүкотторен'ыи рожишагосл и/с тевє 45. Im Troparion ist die Rede davon, dass das hl. Mandylion das „Zeugnis“ und der „Beweis“ (aksl. съљказаниє, vgl. SJS IV 270 s. v.) der Verkörperung von Gottes Sohn ist. Die Substantivform с'ъказания darf man als Akk. pl. oder verderbten Akk. sg. (statt des ursprünglichen *съьказаниє) auffassen. Die Variante ськазания findet sich in den altserbischen Quellen des Kanons (D 104; BM 295v). Nach der Bedeutung des Substantivs съқказанив lässt sich als grie-

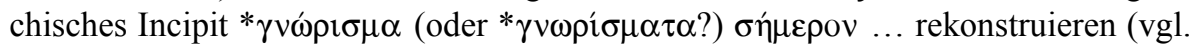
„... ськазание въры ( $\gamma \nu \omega ́ \rho \imath \sigma \mu \alpha)$. Гр.Наз., 87. ХІ в.“ [СлРЯ 11-17 вв. 24: 164]).

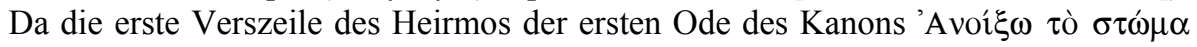

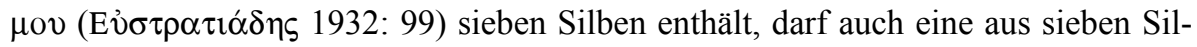
ben bestehende Variante für die Rekonstruktion vorausgesetzt werden $\left({ }^{*} \gamma \nu \omega \rho i ́ \sigma \mu \alpha-\right.$

${ }^{12}$ Die einzige Ausnahme ist der von Konstantin von Preslav übersetzte Kanon des hl. Johannes von Damaskus auf die Geburt Christi. In der Übersetzung wurde die ursprüngliche griechische Akrostichis überarbeitet und der Name Konstantins eingeführt (Попов 1998, 2003).

13 „Bisogna anzitutto osservare che la presenza nei theotokia del nome dell'autore non costituisce un dato matematicamente sicuro per l'atribuzione del canone: è possibile in fatti che i theotokia, dato il loro contenuto generico di carattere mariano e la loro costante presenza nel canone, vengano spostasi da un inno all'altro, purchè siano composti secondo lo schema metrico, cioè l'irmo, desiderato. Questo fatto si verifica più di una volta nei canoni che ho avuto sott'occhio" (Follieri 1964: 316-317).

14 Die Theotokia unseres Kanons wurden nicht aus den anderen Kanones auf die Übertragung des hl. Mandylions übernommen, soweit man aus den Editionen entnehmen kann

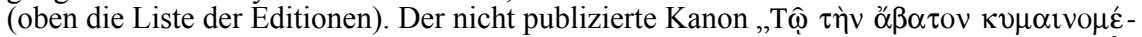
vๆv $\theta \alpha \dot{\alpha} \lambda \alpha \sigma \sigma \alpha v^{\prime \prime}$ (Sin550, f. 375v-376v) enthält Theotokia mit folgenden Incipita: Oî $\alpha$

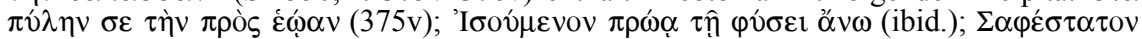

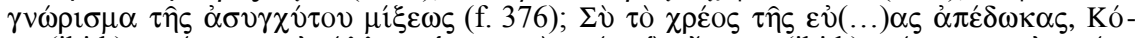

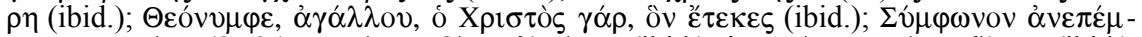

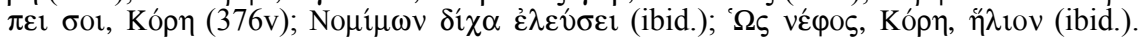
Die ersten Buchstaben der Theotokia gehören zur Akrostichis des Kanons. 


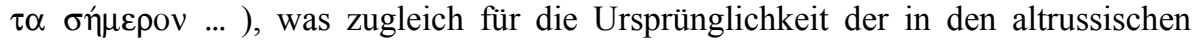
Handschriften befindlichen Lesart съвказания spricht.

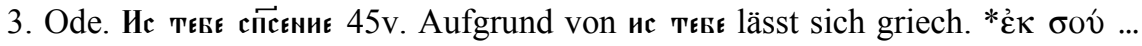
rekonstruieren (Plank - Lutzka 2006: 1059).

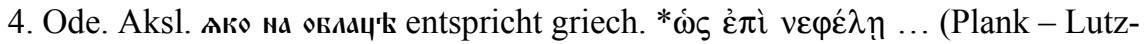
ka 2006: 1059).

5. Ode. Аа капаүть стьвъыше - овлаци бемьнтыи/ать сладость 46. Am Anfang dieses Troparions begegnet man einem hymnographischen Topos. Follieri bietet vier-

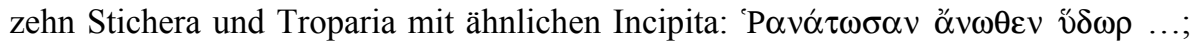

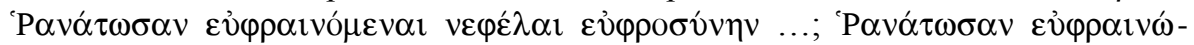

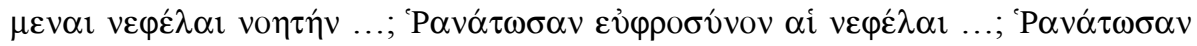

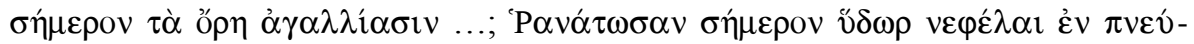

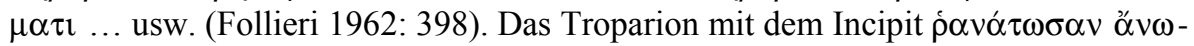

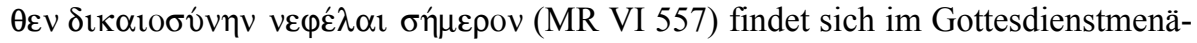

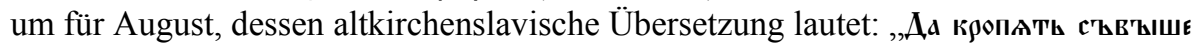

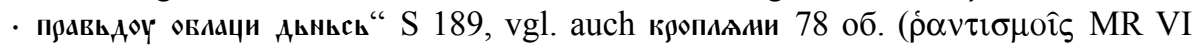
479). Die hymnographischen Parallelen lassen das Incipit * ${ }^{\prime} \alpha \nu \alpha ́ \tau \omega \sigma \alpha \nu ~ o ̈ v \omega \theta \varepsilon v$ ( $\alpha i) v \varepsilon \varphi \varepsilon ́ \lambda \alpha \imath$... rekonstruieren (vgl. Plank - Lutzka 2006: 1059).

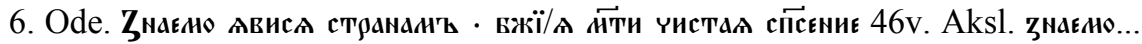

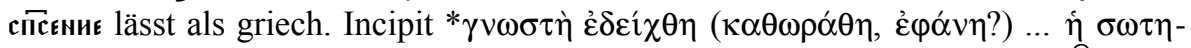

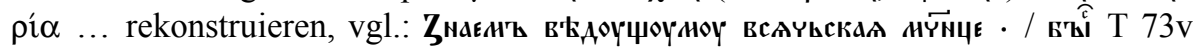

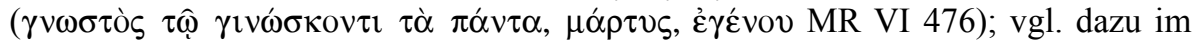
Theotokion der ersten Ode des gemeinsamen Kanons auf die zehn Martyrer von

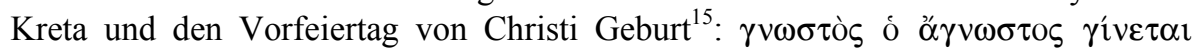
AHG IV 577.

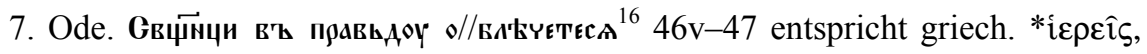

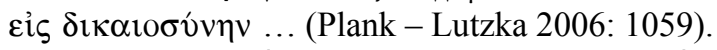

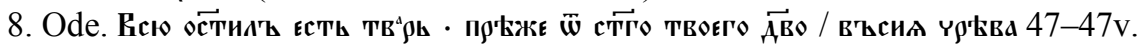

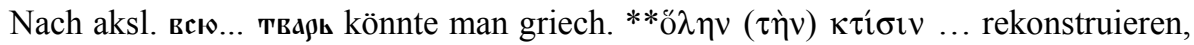
doch ist diese Wortverbindung in den altgriechischen und byzantinischen Texten un-

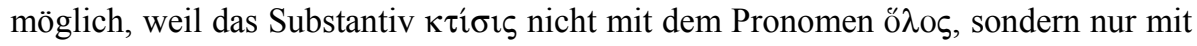
$\pi \hat{\alpha} \varsigma$ verbunden wird (Liddell - Scott - Jones 1996: 1003; Lampe 1961: $782-783$ [s.

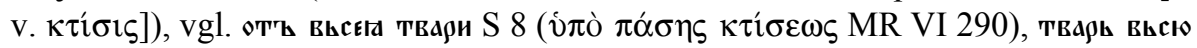

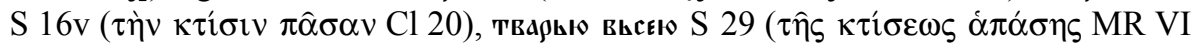

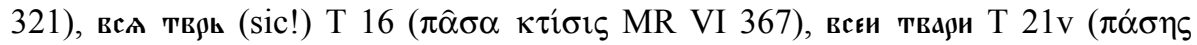

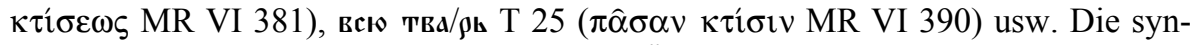
taktische Analyse der altkirchenslavischen Übersetzung bietet eine wahrscheinli-

${ }^{15}$ Der Kanon enthält die alphabetische Akrostichis aus den ersten Buchstaben der gewöhnli-

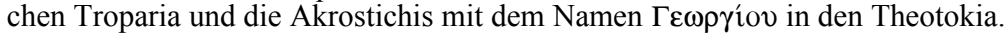

16 Statt овл'tu'téce als Ergebnis des sog. Cokanje. 
chere Rekonstruktion des Incipits. Die grammatische Struktur des altkirchenslavischen Theotokions ist ohne griechisches Original kaum zu verstehen, weil sie wahrscheinlich im Übersetzungsvorgang oder in der handschriftlichen Überlieferung stark entstellt wurde. Dennoch kann man eine wichtige syntaktische Eigenschaft des ersten einfachen Satzes erkennen, nämlich das Fehlen des Subjekts, das sich im verlorenen griechischen Original befand.

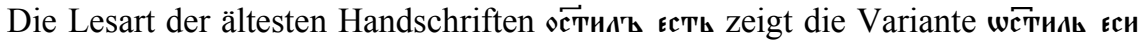
D 106v, woraus die Fehlübersetzung остилъ єси statt *остивъ entnommen werden kann, vgl. das altkirchenslavische Perfekt просв'ттил'ъ єстьь T $11 \mathrm{v}$ als Übersetzung des griechischen Aorist-Partizips к $\alpha \tau \gamma \lambda \lambda \alpha \hat{i} \sigma \alpha \varsigma$ MR VI $358^{17}$. Nimmt man die Lesart остилъ єстьь oder шеттиль єси als Ergebnis einer Fehlübersetzung oder Verderbnis eines ursprünglichen Partizips in Subjektfunktion (остил' griech. $\dot{\alpha} \gamma(\alpha \sigma \alpha \varsigma)$ an, darf man griech. *ó „der“ an den Anfang des griechischen Sat-

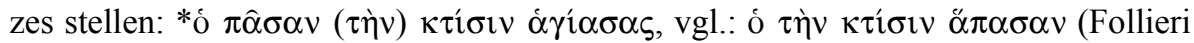

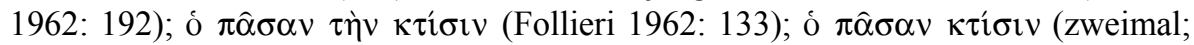
Follieri 1962: 132). Vor einem Partizip in Subjektfunktion konnte der Artikel in den altkirchenslavischen Übersetzungen oft unübersetzt bleiben: В'ъсєкив'ынсл господы .

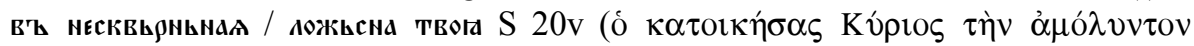

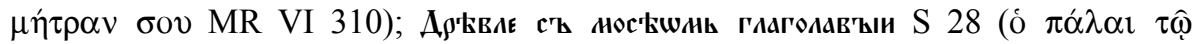

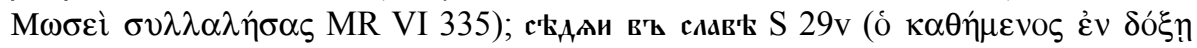

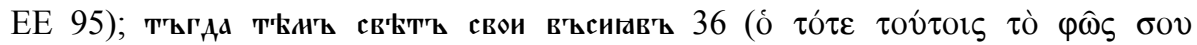

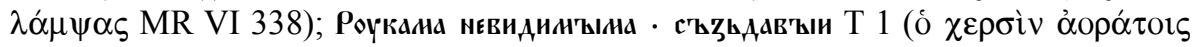

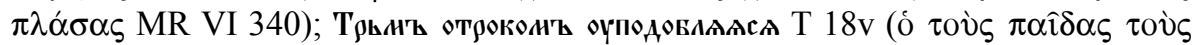

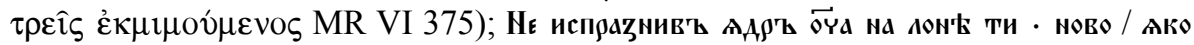

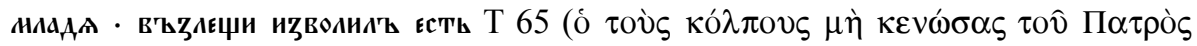

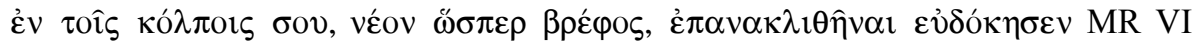
458) usw ${ }^{18}$.

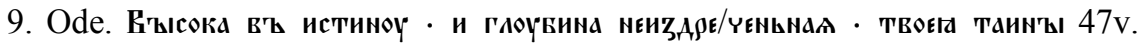

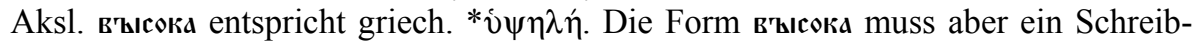
fehler sein, weil sie mit den anderen Satzgliedern syntaktisch nicht verbunden ist. Anscheinend stand als Antithese zu гдоүвина in der ursprünglichen Übersetzung das Substantiv * в'ысота wie in einer der altserbischen Quellen: высота D 107 (in der zweiten altserbischen Handschrift fehlen die Theotokia der 8. und 9. Ode); folglich

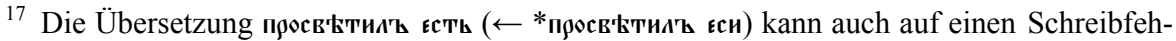

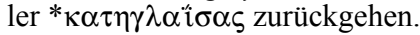

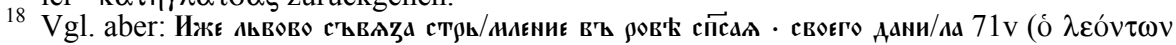

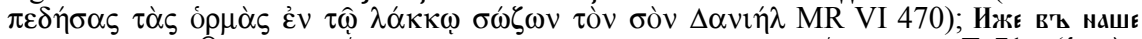

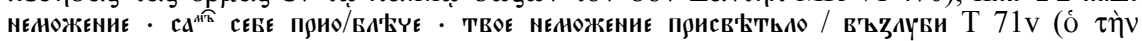

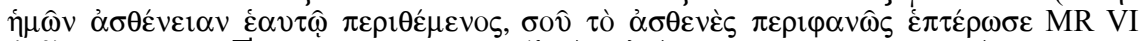

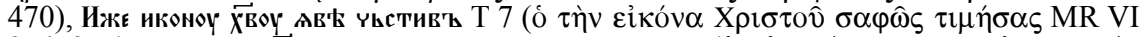

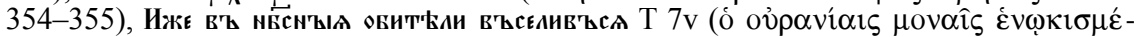
vos MR VI 355). 


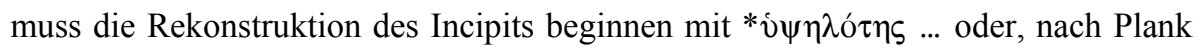
und Lutzka, ర̃\%o૬ (Plank - Lutzka 2006: 1059).

Auf der Basis der über die altkirchenslavische Übersetzung zurückgewonnen griechischen Incipita der Theotokia lässt sich auch der Name des Verfassers (* $Г \varepsilon \omega \rho \gamma i ́ o v$, ,[von] Georgios“) des Kanons auf die Übertragung des hl. Mandylions wiederherstellen. Das heißt, dass es im ursprünglichen griechischen Text des Kanons zwei Akrostichides gab: eine alphabetische in den gewöhnlichen Troparia und eine mit dem Namen des Autors in den ersten Buchstaben der Theotokia, welche nur auf Grund der altkirchenslavischen Übersetzung rekonstruiert werden kann. Die Alphabetakrostichis ist eine der ältesten akrostichischen Formen der byzantinischen Hymnographie und rührt aus der althebräischen (bzw. alttestamentlichen) Poesie her

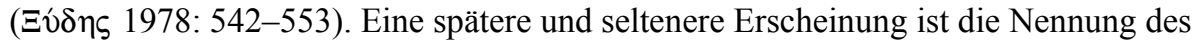
Autornamens in den Theotokia, vor allem, weil die Theotokia als festes Strukturelement des Kanons erst im 9. Jh. eingeführt wurden (Onasch 1981: 359; Weyh 1908: 66-68): „Es kommt, wohl zuerst im Kloster Studion, die Sitte auf, die Theotokia mit dem Namen des Verfassers zu schmücken“ (Weyh 1908: 55) ${ }^{19}$. Die Identifikation des Verfassernamens nach den Anfangsbuchstaben der Theotokia kann dabei manchmal kompliziert sein ${ }^{20}$.

Die Kombination beider Akrostichides, der alphabetischen und der mit dem Namen des Verfassers in den Theotokia, ist eine noch spätere und seltenere Erscheinung: Nach Weyh taucht die Doppelakrostichis ohne Alphabet in den Troparia und Theotokia erst spät auf und findet sich bei Andreas, Kosmas und Johannes von Damaskus noch nicht. Die wichtigsten Vertreter dieser Kunstform sind Klemens ${ }^{21}$ und Georgios (Weyh 1908: 51). Es ist bezeichnend, dass die Doppelakrostichis der Theotokia in den Klassifikationen von Krumbacher (Krumbacher 1903) und Weyh (Weyh 1908) fehlt und dieser Mangel jahrzehntelang von keinem Forscher behoben

19 „Though no special investigation has been made into that question we may accept W. Weyh's preliminary suggestion that Theotokia are found in Kanones in the first part of the ninth century and are integrated into the acrostics of the Kanons of Theophanes and Joseph Studites in the second quarter of the ninth century. At a later date Theotokia were inserted in Kanons of hymnographers who flourished before Theophanes and Joseph" (Wellesz 1962: 370).

20 „Канон Власию, епископу Севастийскому, глас четвертый. Греческий текст впервые опубликован в AHG VI (1974), но без второй песни и как творение анонимное. Акростиха в каноне нет, а тем самым как будто и нет данных судить, была ли в нем когда-либо вторая песнь. Однако издателем не замечен поврежденный акростих по инициалам феотокионов: 'A $\langle v\rangle \tau \omega v i ́ 0 v$. Это - имя очень редко встречающегося гимнографа. Недостающая вторая буква свидетельствует, что вторая песнь была“ (Мурьянов 1982: 395). Die kirchenslavische Übersetzung der zweiten Ode des Kanons auf den hl. Blasios findet sich in der altrussischen Handschrift des 12.-13. Jh. (РГАДА, ф. 381 [Тип.], Nr. 98, f. 73-74v) (Мурьянов 1982: 395).

21 Klemens war ein byzantinischer Hymnendichter des 9. Jh. und starb in der Verbannung während der zweiten Phase des Bilderstreits; ihm werden 29 Kanones zugeschrieben (Volk 1997: 128). 
wurde (Szövérffy 1979: 4) ${ }^{22}$. So kann man auch den folgenden Hinweis nur als Missverständnis werten: „Gli elementi comuni che legano questo canone [auf die hll. Irene, Agape und Chione - R. K.] con il precedente dedicato a S. Artemone (13 aprile) sono l'achrostico alfabetico che Giorgio usa spesso e il nome dell'autore nell'acrostico dei $\theta \varepsilon о \tau$ - 1 í $\alpha$. A proposito di questo ultimo caso basta rinviare il lettore agli studi del Weyh e del Krumbacher" (AHG VIII: 413; kursiv von mir - R. $K$.). Es ist aber hervorzuheben, dass die Herausgeber und Kommentatoren der AHG die alphabetische Akrostichis mit dem Verfassernamen in den Theotokia zu Recht für eine wichtige stilistische Gemeinsamkeit der beiden Kanones halten.

Solche Kombinationen von Akrostichides sind nur aus den Kanones des Georgios wohlbekannt. Während Krumbacher und Weyh meist publizierte Kanones erforschten $^{23}$, untersuchte Papailiopulu-Photopulu Hunderte byzantinischer Gottesdienstmenäen und entdeckte 899 unedierte Kanones. Im Register neu entdeckter Ka-

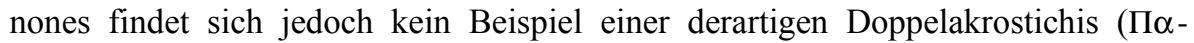

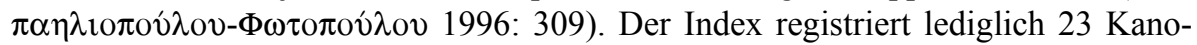
nes mit alphabetischer Akrostichis (darunter den Kanon auf die Übertragung des hl. Mandylions) sowie sechs Kanones, die nach dem Schluss der alphabetischen Akrostichis in der besonderen Akrostichis der 8. und 9. Ode den Namen des Autors

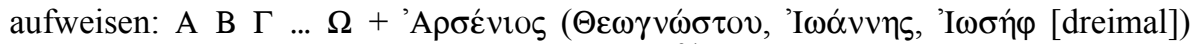

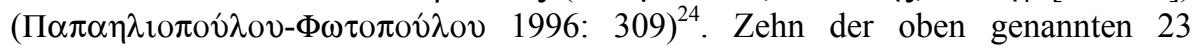
Kanones enthalten aber nicht einfache alphabetische, sondern Doppelakrostichien

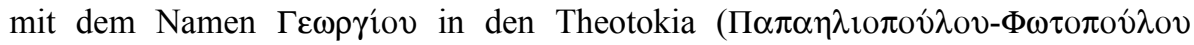
1996: 139, Nr. 399; 111, Nr. 300; 122, Nr. 338; 160, Nr. 470; 201, Nr. 609; 211, Nr. $643 ; 217$, Nr. 665; 225, Nr. 691; 266-267, Nr. 833; 271, Nr. 849). Diese wichtige Eigenschaft wird im Register nicht vermerkt. Follieri stellte noch sechs Kanones mit

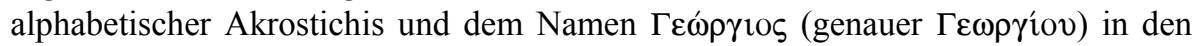
Theotokia fest (Follieri 1964: 315). Es ist aber unklar, welche Kanones sie im Einzelnen meinte; vier von diesen Kanones dürften freilich später von Schirò herausgegeben worden sein (AHG XIII: 325 [Index]). In seiner Edition gibt es noch zwei Kanones mit einer derartigen Doppelakrostichis, aber mit anderen Namen: $\tau 0 \hat{v}$

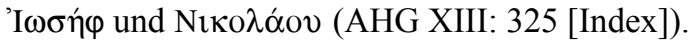

22 S. auch die Übersicht über die wichtigsten Monographien im Bereich der byzantinischen Hymnographie, die in der zweiten Hälfte des 20. Jh. erschienen sind: Hannick 2005: 364 366. Dabei begründet Hannick den rudimentären Forschungsstand der (alt)kirchenslavischen Akrostichis mit dem Fehlen einschlägiger Untersuchungen zu deren byzantinischen Vorlagen (Hannick 1973: 151, 153). Zu den wichtigsten Werken über die Akrostichis in der altkirchenslavischen liturgischen Dichtung s. Hannick 1973; Попов 2003.

23 Krumbacher beschäftigte sich nur mit den Akrostichides in den Kontakia.

24 In einem Kanon ist die alphabetische Akrostichis durch folgende Phrase ergänzt: ' $\Omega \delta \grave{\eta}$

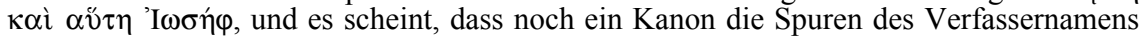
in den ersten Buchstaben der 9. Ode enthält: $\Omega H\left(\leftarrow{ }^{*} \mathrm{I} \underline{\omega} \sigma \underline{\eta} \varphi\right.$ ?). 
Ob die Doppelakrostichis mit dem Alphabet in den gewöhnlichen Troparia und dem Namen $\Gamma \varepsilon \omega \rho \gamma$ íov in den Theotokia wirklich die individuelle Eigenschaft ein und desselben unbekannten Hymnographen ist, könnte man nur auf Grund einer kritischen Edition aller Georgios zugeschriebenen Kanones beurteilen; vgl. das Urteil Enrica Follieris, die sich besonders mit den Kanones des Georgios beschäftigt hat: „Fra i problemi di omonimia, di notevole interesse è quello relativo agli innografi bizantini che recarono il nome di Giorgio ... E sopratutto numerosi sono i canoni, per la massima parte inediti, in cui il nome di Giorgio appare nell'acrostico dei theotokia, senza alcuna altra specificazione" (Follieri 1964: 313-314). Von 103 bekannten Kanones ${ }^{25}$ mit dem Namen $\Gamma \varepsilon \omega \rho \gamma$ íov in den Theotokia wurden 48 von Follieri erforscht; sechs von ihnen enthalten die Doppelakrostichis mit Alphabet in den gewöhnlichen Troparia. Follieri hielt zunächst auf Grund stilistischer Befunde Georgios von Nikomedien für den Autor dieser Kanones (Follieri 1964), lehnte aber ihre

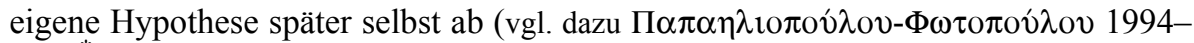
$1995^{*}$ ). Da es keine strikten Kriterien gibt, nach denen man feststellen könnte, welcher Kanon von Georgios von Nikomedien und welcher von einem anderen unbekannten Verfasser mit demselben Namen geschrieben worden ist, kam Follieri zum Schluss, dass nur die Kanones auf die Gottesmutterfeste Georgios von Nikomedien sicher zugeschrieben werden können (Follieri 1966: 261-262) ${ }^{26}$. Diese Deutung stimmt mit der Meinung von Hans-Georg Beck überein, der seinerseits die ältere Argumentation von Émerau wiederholt ${ }^{27}$ : „Ob es sich immer um denselben Georgios handelt und ob er wirklich der Zeit des Bilderstreites angehört, ist absolut unsicher. Jedenfalls scheint es einen Hymnographen Georgios gegeben zu haben, dessen besonderes Anliegen Marienkanones gewesen sind“ (Beck 1959: 519). Georgios von Nikomedien kann nicht der Autor des Kanons auf die Übertragung des hl. Mandylions (944) sein, weil er nach 880 gestorben ist (zu seinen Lebensdaten s. Varnalidis 1995: 484). Die von ihm der Gottesmutter gewidmeten Kanones enthalten keine alphabetischen Akrostichides (Follieri 1966: 262). Nur ein Kanon von Georgios von

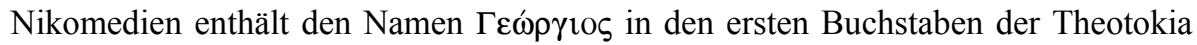
(Follieri 1966: 262), aber ohne Akrostichis in den gewöhnlichen Troparia: $\Delta o ́ \xi \alpha \tau \hat{n}$

${ }^{25}$ Nur zwanzig von ihnen wurden publiziert.

* Der Aufsatz ist mir nicht verfügbar. Kurz vor der Korrektur teilte mir Dr. Aleksandra Nikiforova (Moskau) die bibliographische Angabe freundlicherweise mit.

${ }^{26}$ Vgl.: ,... denn von 300 Meloden ist etwa der dritte Teil nur durch die A n f a n g s $\mathrm{b} \mathrm{u}$ ch stabe n d e r S r o p h e n bekannt. Freilich hilft der bloße Name nicht immer zur genaueren Bestimmung, weil viele Homonyme vorkommen. Besonders herrscht unter den zahlreichen Trägern der Namen $\mathrm{T}$ h e o d o r o s, G e o r g i o s , J o h a $\mathrm{n} n$ e s eine schwer zu lichtende Verwirrung“" (Krumbacher 1897: 337).

27 „Equidem difficile est certo notare discrimine omnes illos melodos qui sub nomine Georgii inveniuntur apud Byzantinos. ... Notare etiam juvabit unum certo exstetisse Georgium qui Deiparae mysteriis operam dedit, uti patet ex carminibus modo citatis" (Emerau 1923: $424-425,425)$. 


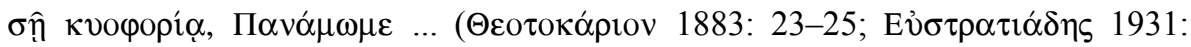
188-191).

Émerau bietet eine umfangreiche Liste von 22 Kirchendichtern mit dem Namen

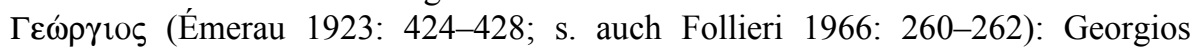

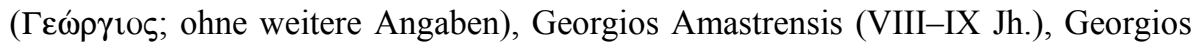
Anatolius, Georgios Bardanes (XIII Jh.), Georgios Choniates (XII Jh.?), Georgios Chrysogonus (XVIII Jh.), Georgios Coressius (,nat. ca. 1650?“ [Emerau 1923: 425]), Georgios Cretensis (XVIII-XIX Jh.), Georgios Eugenicus (,diaconus, et

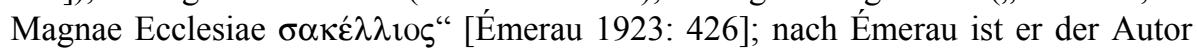
einer Akolouthie auf den hl. Spyridon), Georgios Hagiopolita, Georgios Lesbius (,auctor paracletici ad s. Nicolaum“ [Émerau 1923: 426]), Georgios Nicomediensis (IX Jh.), Georgios Pisida (VII Jh.), Georgios Papadopulus (XVIII Jh.), Georgios Rammata (XIV Jh.), Georgios Sassus (XIX Jh.), Georgios Scylitza (XII Jh.) (Émerau 1923: 426-427), Georgios Sikeliotes ${ }^{28}$, Georgios Sypandrus (XVIII Jh.), Georgios Syracusanus (VII Jh.), Georgios Trapezuntius (XV Jh.), Georgios Velimas (XVIII Jh.). Da die Übertragung des hl. Mandylions 944 stattfand, ist dies der terminus post quem des gesuchten Georgios. Obwohl die älteste byzantinische Handschrift erst ins 12. Jh. datiert wird, dokumentieren die ältesten kirchenslavischen Quellen bereits einen Stand der Mitte des 11. Jh. (Momina 1990); folglich ist der terminus ante quem für das Werk von Georgios der Anfang oder die erste Hälfte des 11. Jh. Auf Grund der altkirchenslavischen Übersetzung kommen als mögliche Verfasser des Kanons auf das hl. Mandylion nur diejenigen Autoren von Émeraus Liste in Frage, deren Lebenszeit in die Zeitspanne zwischen 944 und der Mitte des 11. Jh. fällt.

Hymnographen des 10.-11. Jh. ${ }^{29}$ sind Georgios Anatolius, Georgios Hagiopolita, Georgios Siceliotes, Georgios Eugenicus, Georgios Lesbius und insbesondere Georgios, der nur von der hier behandelten Akrostichis bekannt ist. Gemäß der Stilanalyse von Follieri dürfen die ersten drei Kirchendichter, welche Autoren mehrerer Heirmoi sind, nicht die Verfasser der Kanones mit der Akrostichis $\Gamma \varepsilon \omega \rho \gamma$ íov in den Theotokia sein (Follieri 1964: 313-315). Auf Grund der wenigen Angaben, die die Byzantinistik zur Zeit besitzt, darf man zum Schluss kommen, dass der wahrscheinlichste Autor des Kanons auf die Übertragung des hl. Mandylions der unbekannte Georgios ist, dem bis zu 100 Hymnen mit seinem Namen in den Theotokia zugeschrieben werden. Der wahre Umfang seines Werkes bleibt unbekannt. Eine stilistische Eigenschaft der Hymnen dieses Autors dürfte die Benutzung der alphabeti-

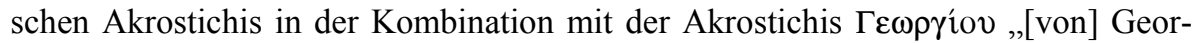
gios“ in den Theotokia sein. Die altkirchenslavische Übersetzung des Kanons bietet

\footnotetext{
28 Tomadakis hält Georgios Sikeliotes und Georgios von Nikomedien für denselben Autor

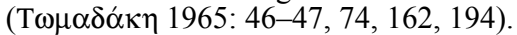

29 D. h., dass man keine Angaben über die Lebenszeit hat.
} 
Angaben über die Lebenszeit des Autors: Mitte 10. - Anfang 11. Jh. Dieser Hymnograph ist der einzige Kirchendichter mit dem Namen Georgios (abgesehen von dem hl. Georgios von Nikomedien), dessen Lebenszeit uns bekannt ist. Dank der altkirchenslavischen Übersetzung konnte diese Lücke in der Geschichte des byzantinischen liturgischen Schrifttums, wie klein sie auch sein mag, geschlossen werden.

A $n \mathrm{~h}$ a $\mathrm{ng}$ : Der Kanon auf die Übertragung des hl. Mandylions nach den ältesten kirchenslavischen Quellen und sein byzantinisches Original ${ }^{30}$

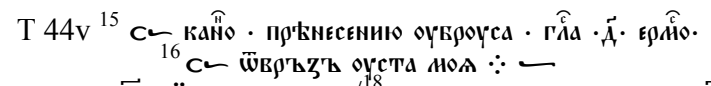

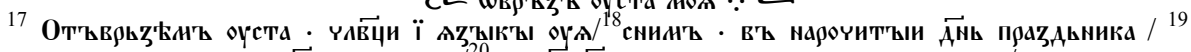

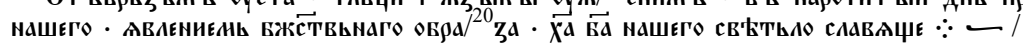

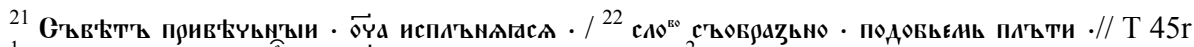

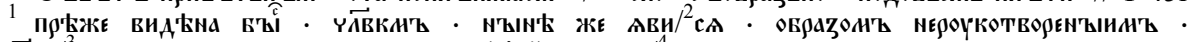

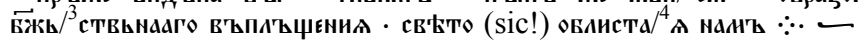

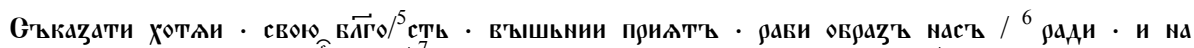

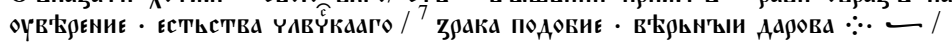

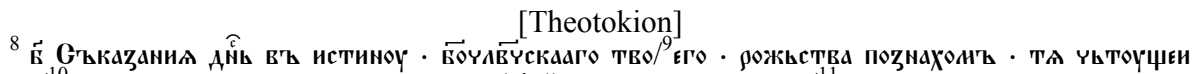

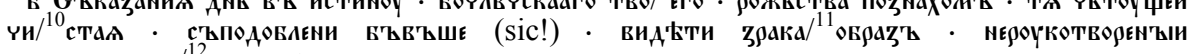

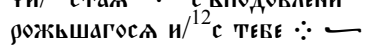

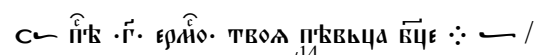

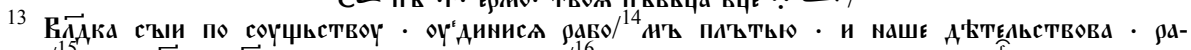

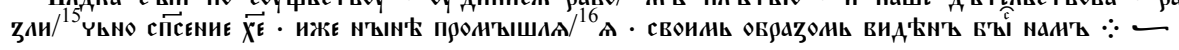

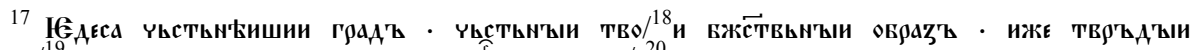

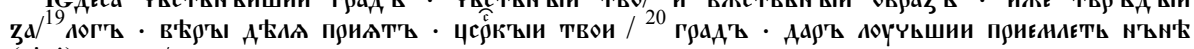
(sic!) $\because-1$

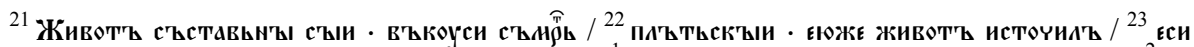

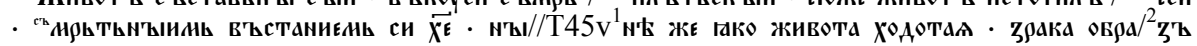
ТВОИ ПОААА'Қ НСИ наА'Қ $\because-$

[Theotokion]

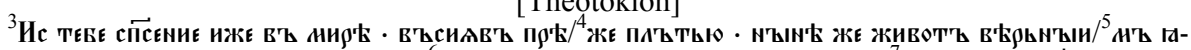

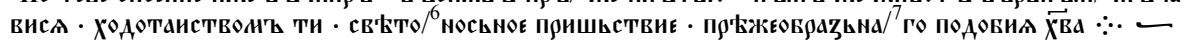

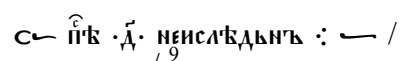

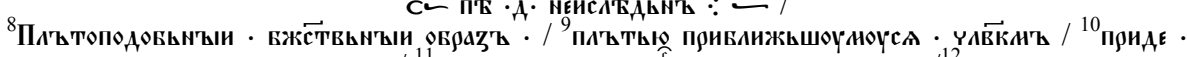

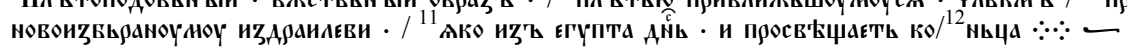

${ }^{30}$ Der griechische Text des Kanons nach der Edition von P. Plank und C. Lutzka (Plank Lutzka 2006: 1112-1115) mit den auf der Basis der altkirchenslavischen Übersetzung wiederhergestellten Incipita der Theotokia. 


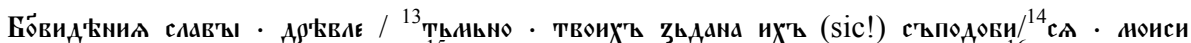

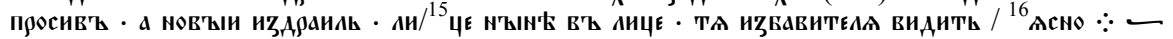

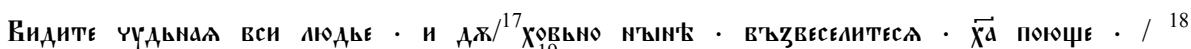

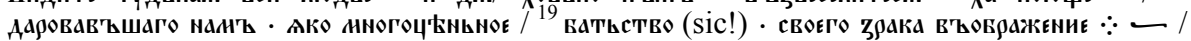

\section{[Theotokion]}

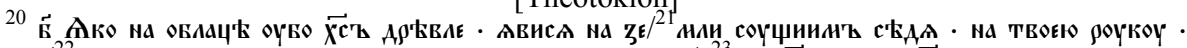

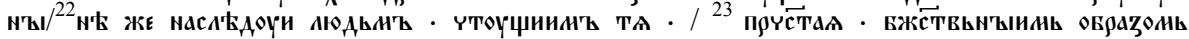
Ависа $\div-/ /$

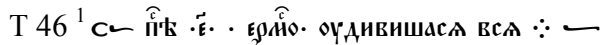

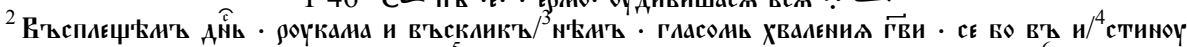

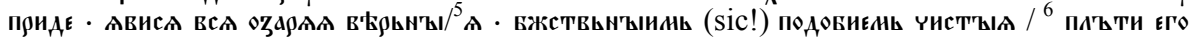
$\because$

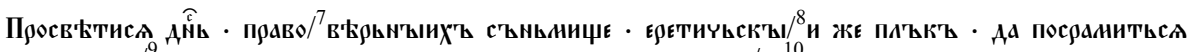

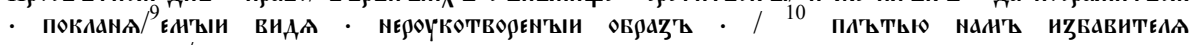
приложьшюс : /

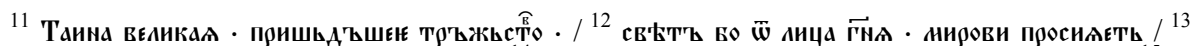

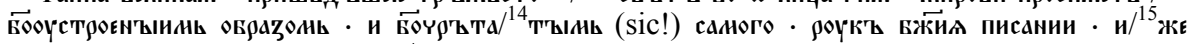

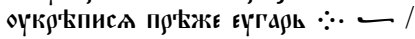

[Theotokion]

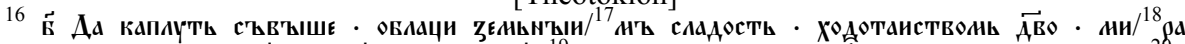

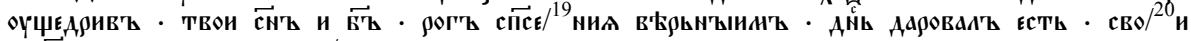
вжстьвьныи ов

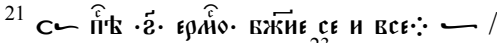

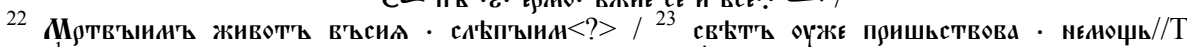

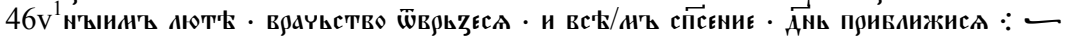

D $105^{31}$

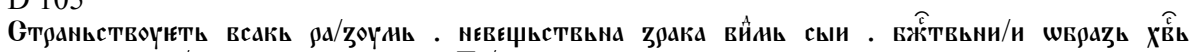

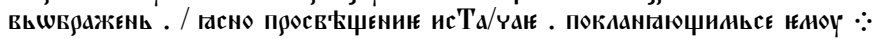

T $46 \mathrm{v}$

${ }^{2}$ Поүти $\overrightarrow{\chi^{\prime}} \mathbf{~}$

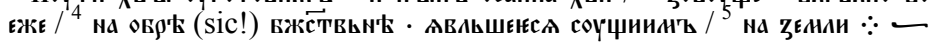

[Theotokion]

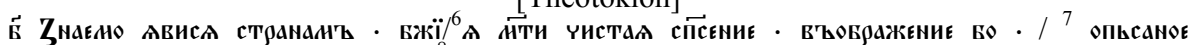

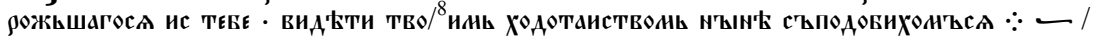

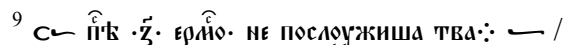

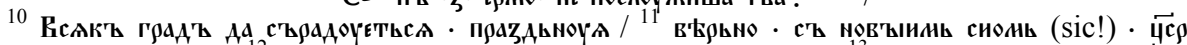

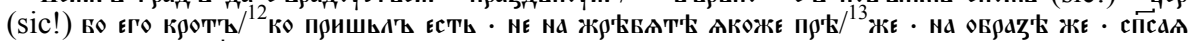
ПоюџАА вТ $\rho \circ ю$ БЕ БА: —।

${ }^{31}$ Das Troparion fehlt in den altrussischen Handschriften. 


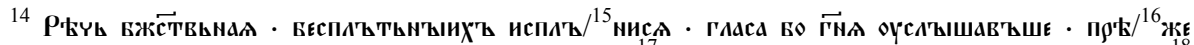

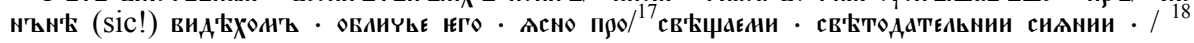
TВOEГО АВАЕНИА $\because$ -

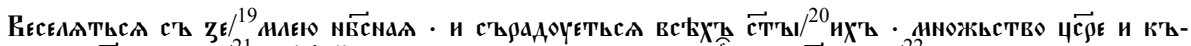

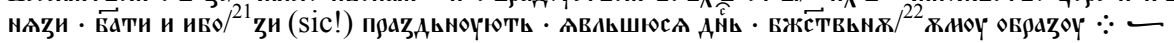

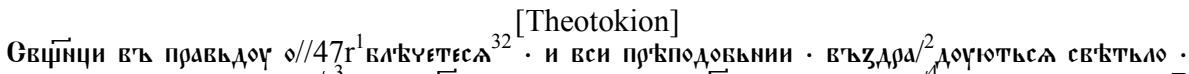

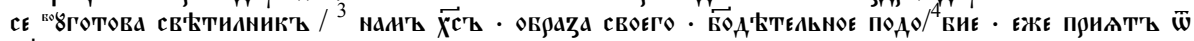
$\overrightarrow{A^{B}} \mathbf{Z} \mathbf{Z}$

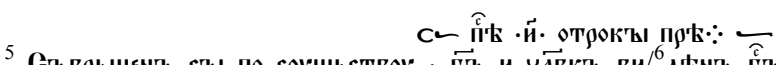

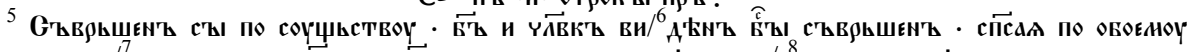

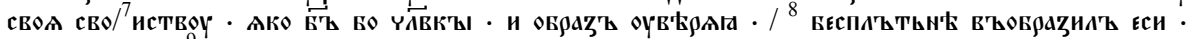

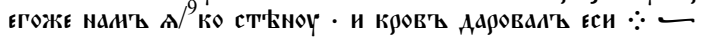

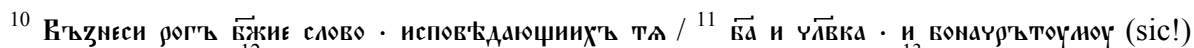

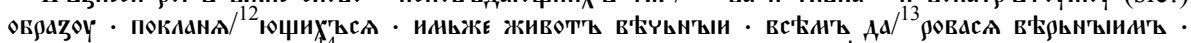

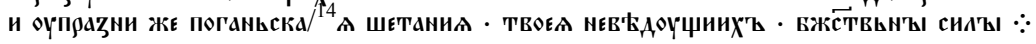

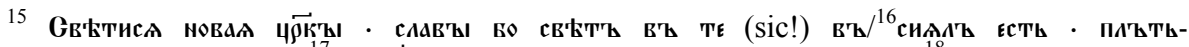

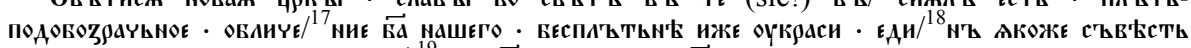

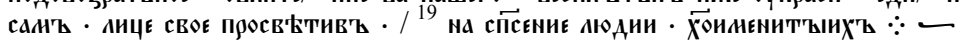

[Theotokion]

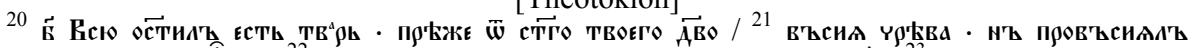

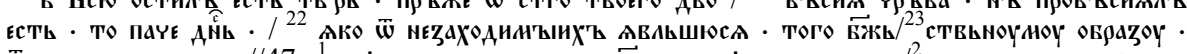

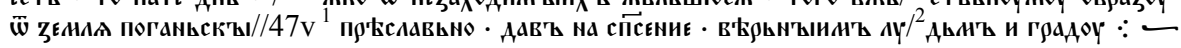

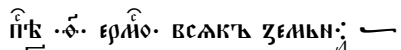

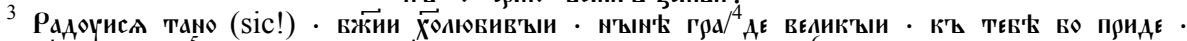

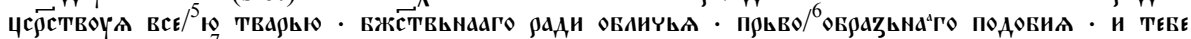

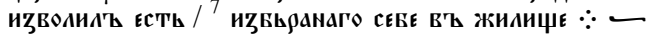

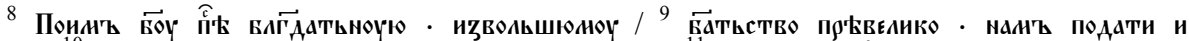

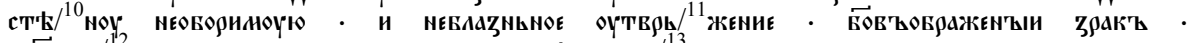

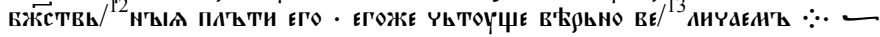

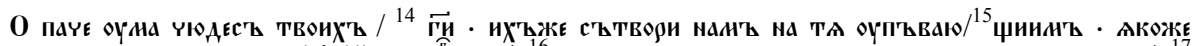

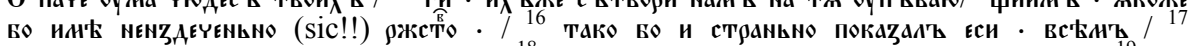

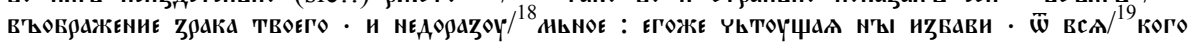
rN'EBA $\because-$

[Theotokion]

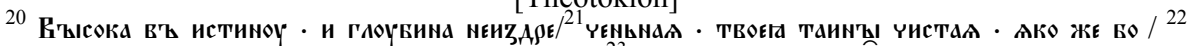

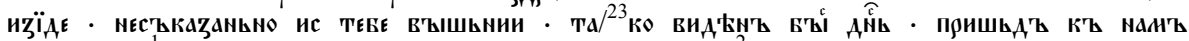

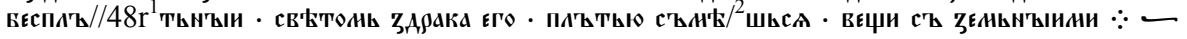

32 овлtYYTTEA steht in beiden altrussischen Handschriften, wahrscheinlich statt ursprüngli-

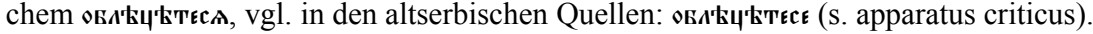




\section{Apparatus criticus}

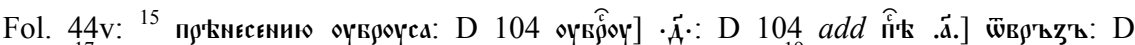

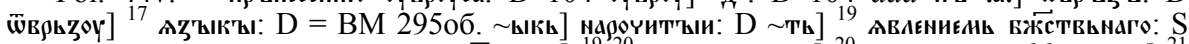

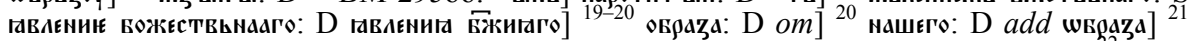

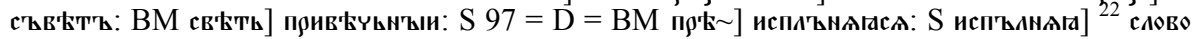

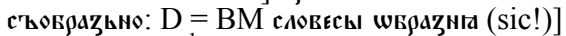

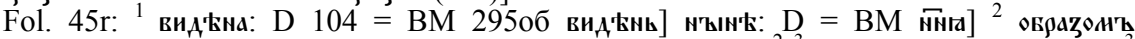

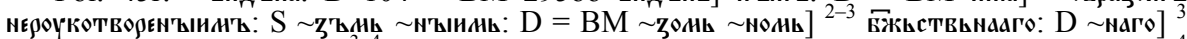

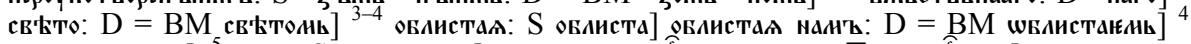

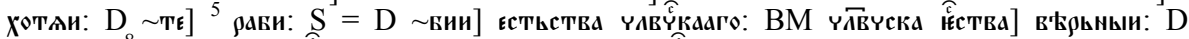

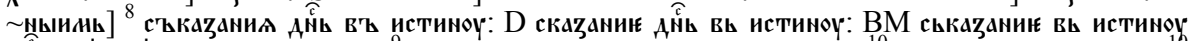

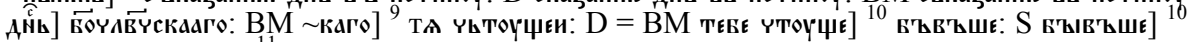

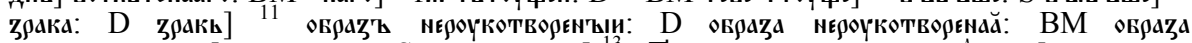

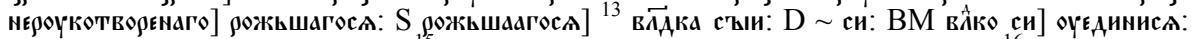

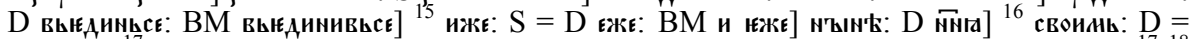

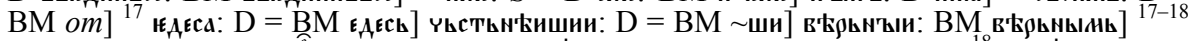

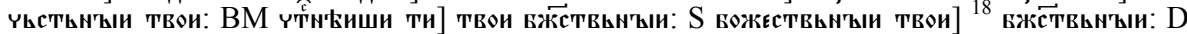

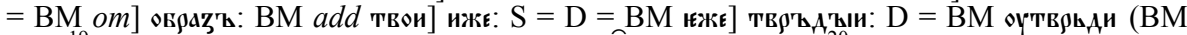

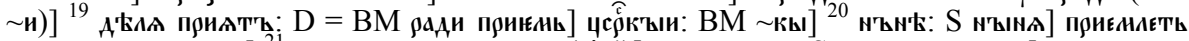
н'ън'Е: $\mathrm{D}=\mathrm{BM}$ om ${ }^{21}$ животъ: $\mathrm{BM}$ кывоть (sic!)] стыставьн'ы: $\mathrm{S} \sim$ н'ын: $\mathrm{BM} \sim$ нь] въқкоүси: $\mathrm{D}$

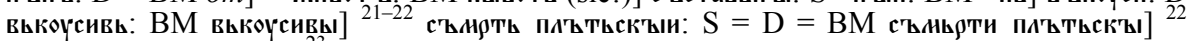

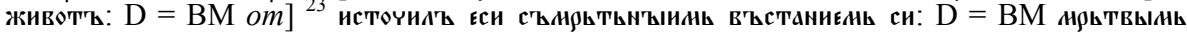
(BM: нотТвынАнь) источнАь нси вьстанин]

Fol. 45v: ${ }^{1} \sim$ N'E: D $104=$ BM $296 \sim$ Nта] живота: D = BM животог] XодотаA: $\mathrm{S}=\mathrm{D}=\mathrm{BM}$

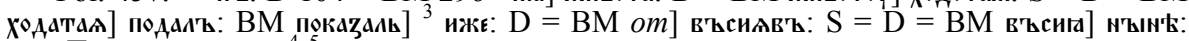

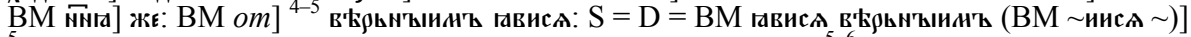

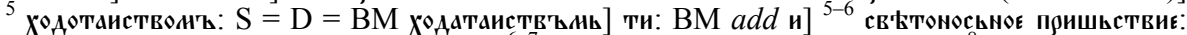

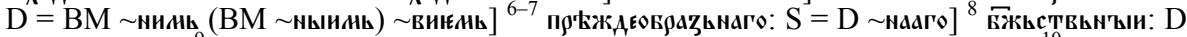
104об. Бжин] ${ }^{9}$ пл'ътью: D = BM пльти] приБлижьшоүноүсе: $\mathrm{S} \sim$ шюоүноүсе] ${ }^{10}$ прнде: D

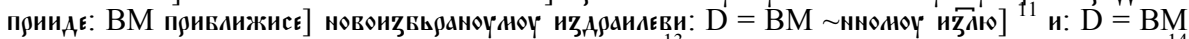
om] просв' просивъ: $\mathrm{D}$ просиавь таино $=\mathrm{BM}$ просивь танно] а нов'ын: $\mathrm{D}=\mathrm{BM}$ от ${ }^{14-15}$ лице: $\mathrm{D}=\mathrm{BM}$

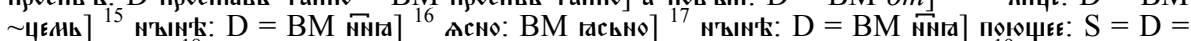

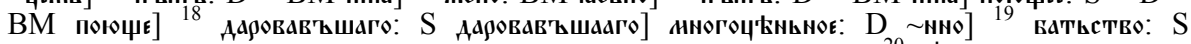

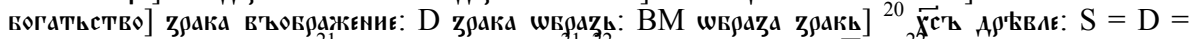

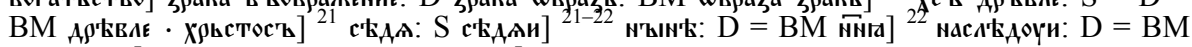

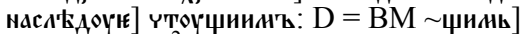

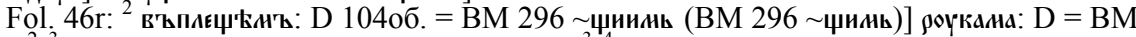

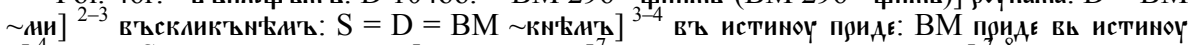

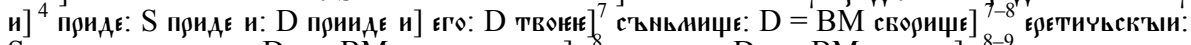

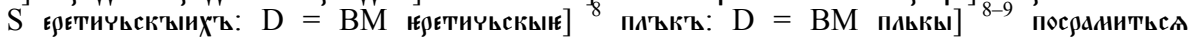

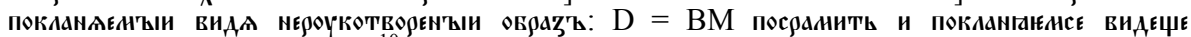

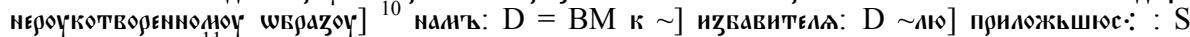

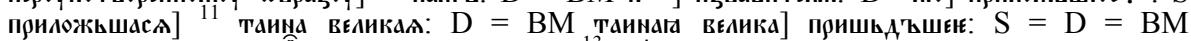

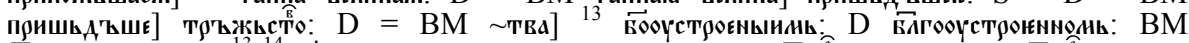

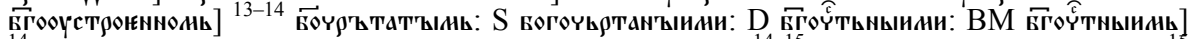

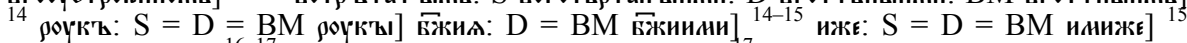

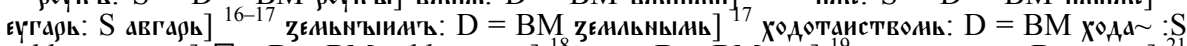

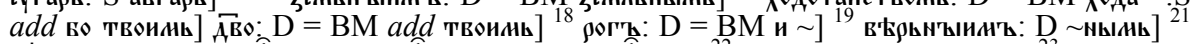

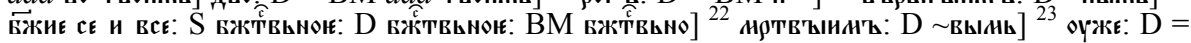
$\mathrm{BM}$ ю\%е]

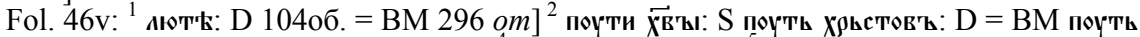

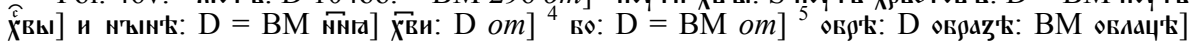

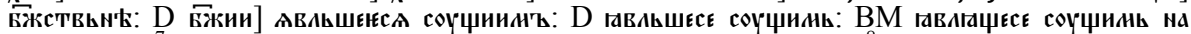

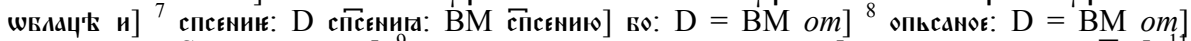

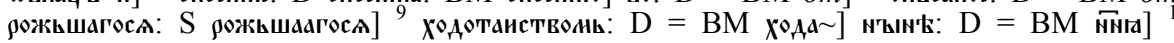




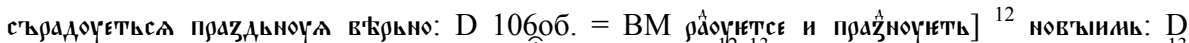

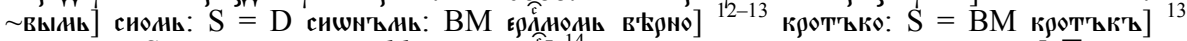

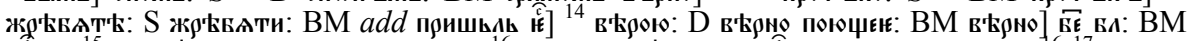

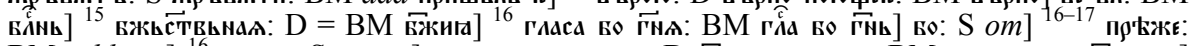

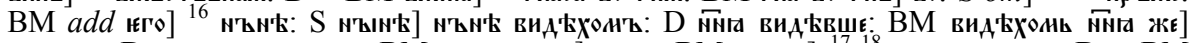

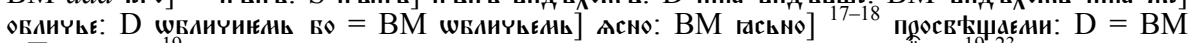

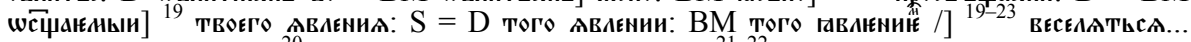

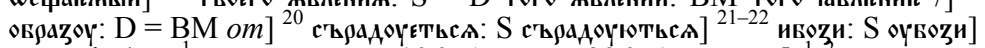

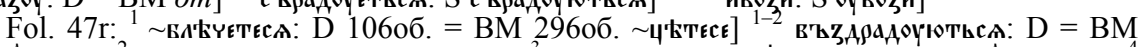

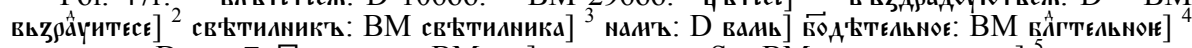

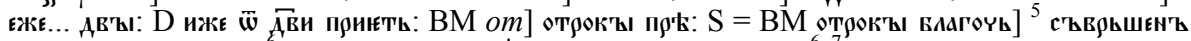

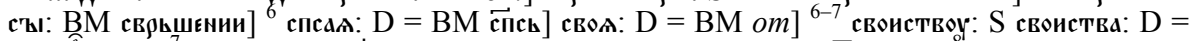

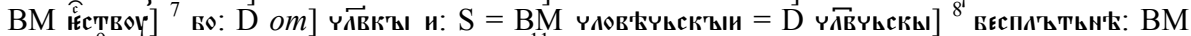

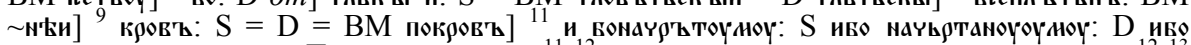

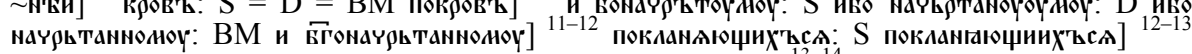

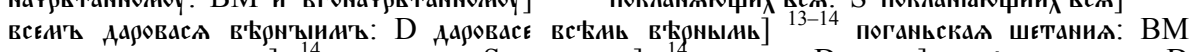

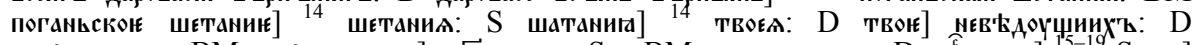

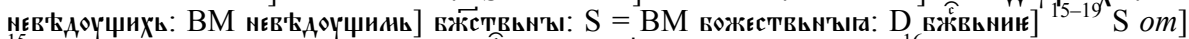

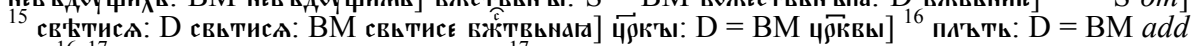

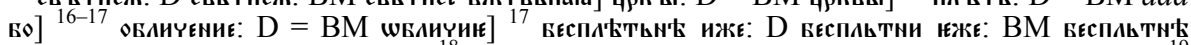

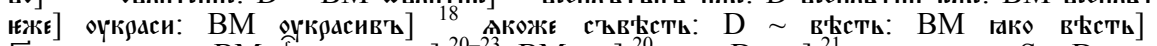

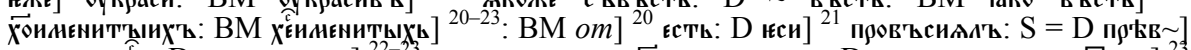

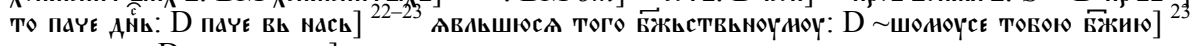
поганьск'ы: D поганьскын]

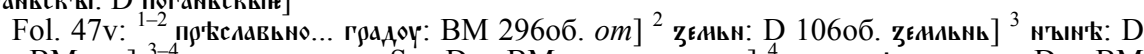

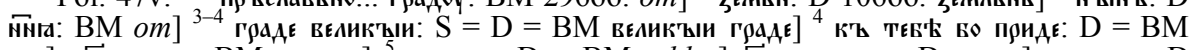

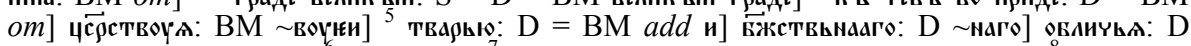

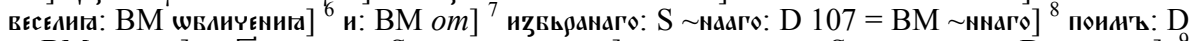

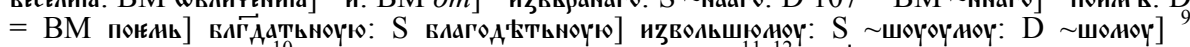

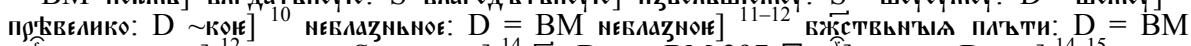

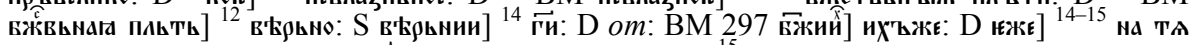

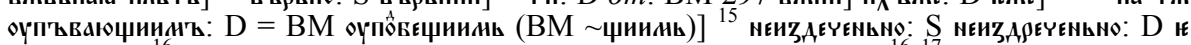

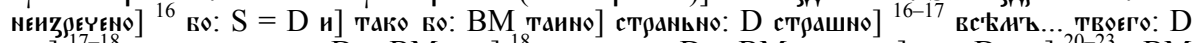

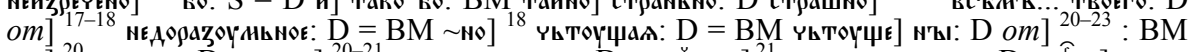

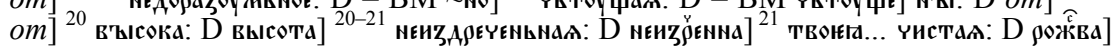

' $\Omega \delta \grave{\eta} \alpha$ '.

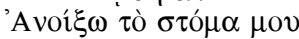

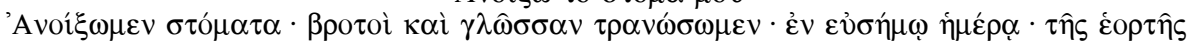

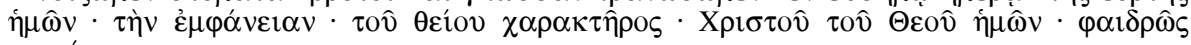

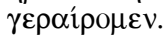

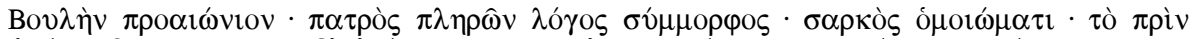

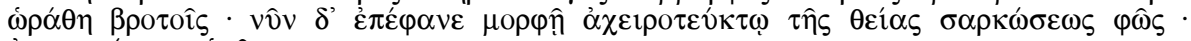

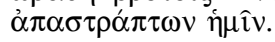

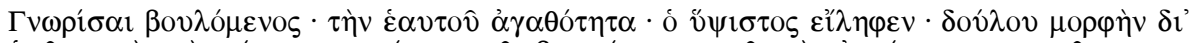

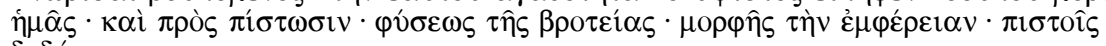

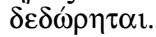

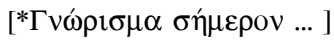

' $\Omega \dot{\delta} \delta \grave{\gamma} \gamma^{\prime}$.

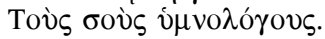

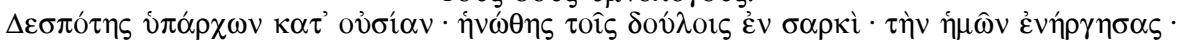




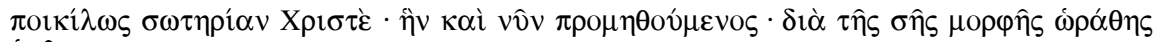

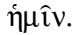

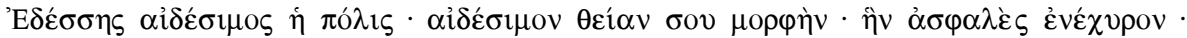

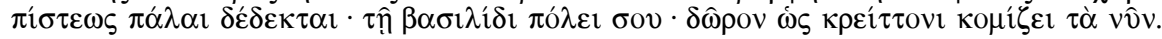

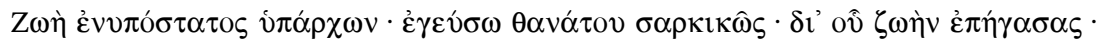

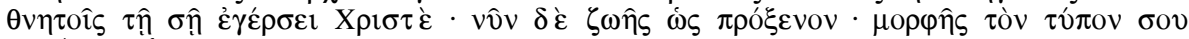

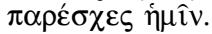

[*'Ек боѝ ... ]

\section{' $\Omega \delta \dot{\eta} \delta$}

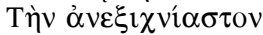

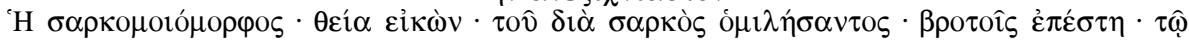

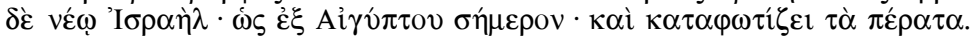

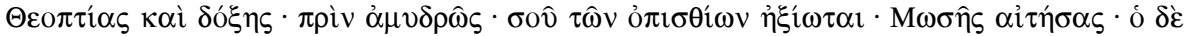

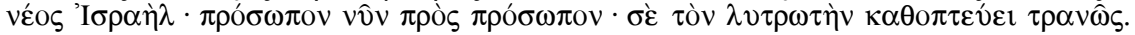

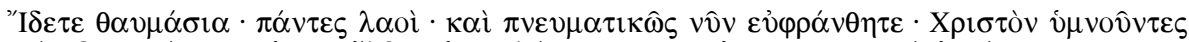

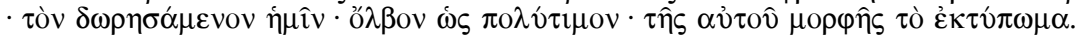

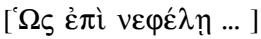

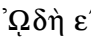

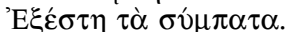

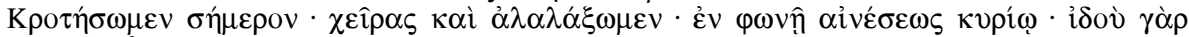

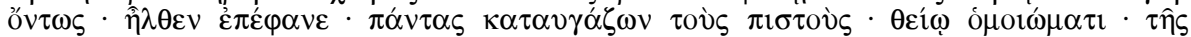

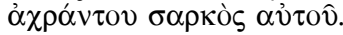

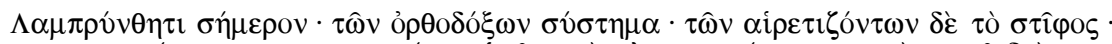

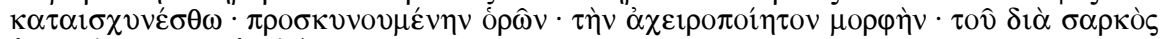

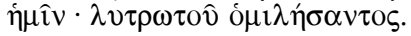

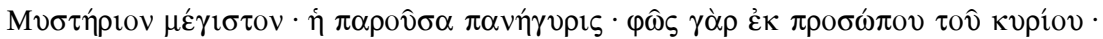

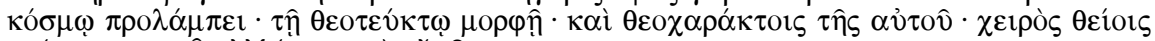

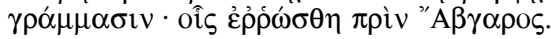

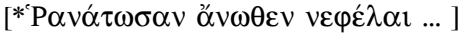

' $\Omega \delta \grave{\eta} \sigma \tau^{\prime}$

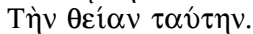

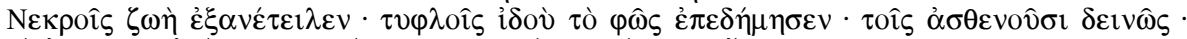

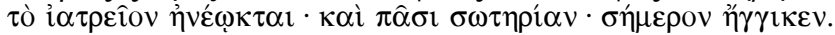

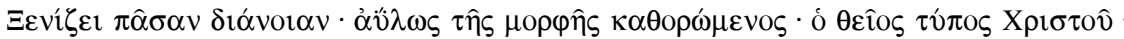

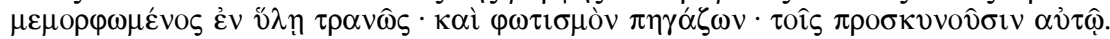

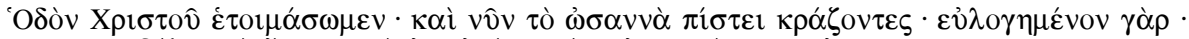

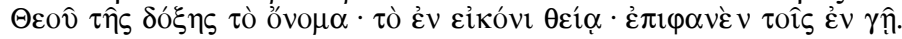

$[* \Gamma \nu \omega \sigma \tau \grave{\eta} \ldots]$

' $\Omega \dot{\delta} \dot{\eta} \zeta^{\prime}$.

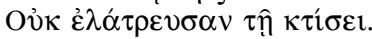

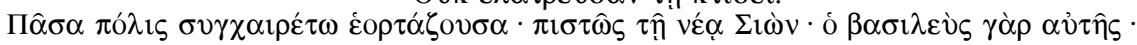




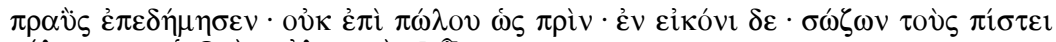

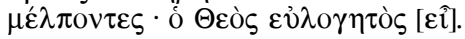

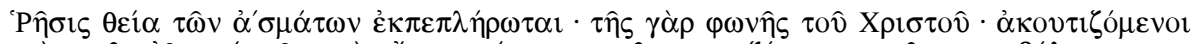

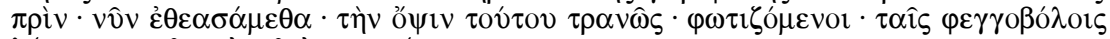
$\lambda \dot{\alpha} \mu \psi \varepsilon \sigma \imath \cdot \tau \hat{\eta} \varsigma \alpha \hat{v} \tau 0 \hat{v} \varepsilon \dot{\pi l} \varphi \alpha v \varepsilon i ́ \alpha \varsigma$.

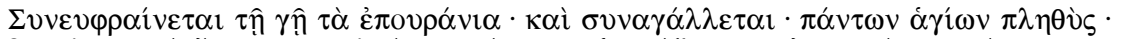

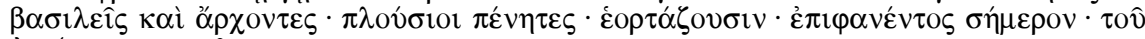

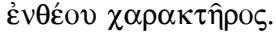

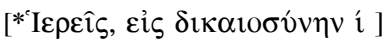

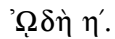

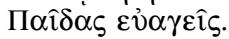

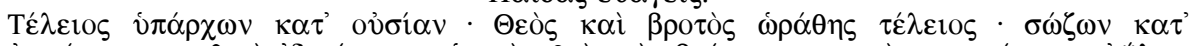

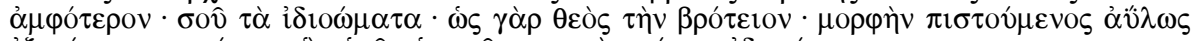

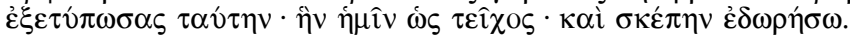

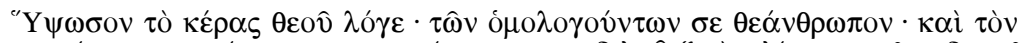

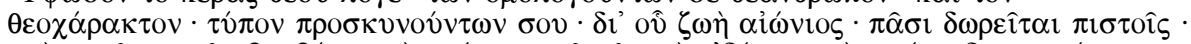

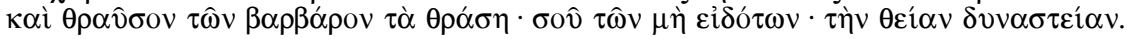

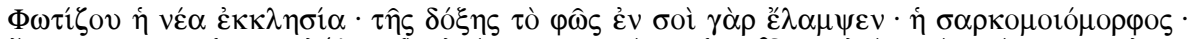

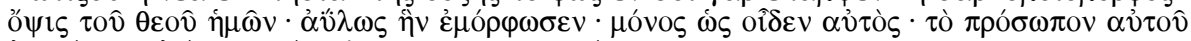

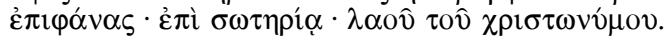

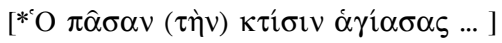

' $\Omega \delta \dot{\eta} \theta^{\prime}$.

"A $\pi \alpha \varsigma \gamma \eta \gamma \varepsilon v \eta \dot{s}$.

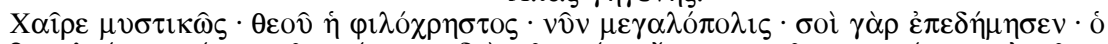

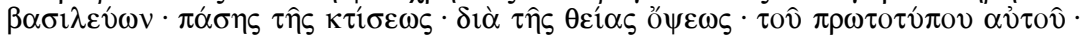

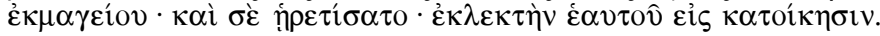

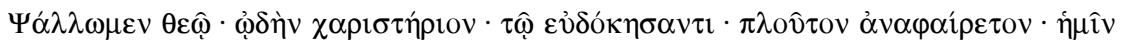

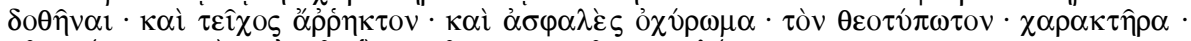

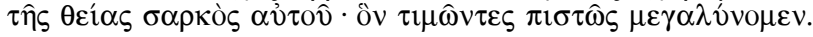

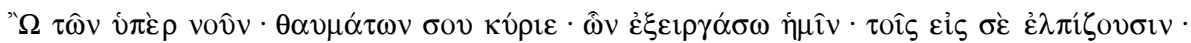

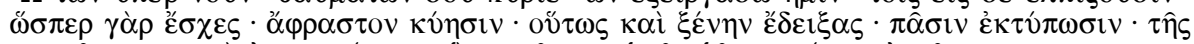

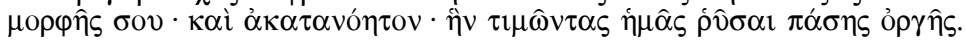

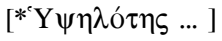

A b k ür z u ng e n

add

AHG I - XIII: $\quad$ Analecta Hymnica Graeca e codicibus eruta Italiae inferioris, J. Schiró

consilio et ductu edita, I-XIII, Roma 1966-1983

BHG I - III: $\quad$ F. Halkin (ed.), Bibliotheca Hagiographica Graeca, t. I-III (= Subsidia Hagiographica, $\left.\mathrm{n}^{\circ} 8 \mathrm{a}\right)$, Bruxelles 1957

$\mathrm{BM}$

Народна библиотека Србије (Београд), „Братков минеј“, Рс. 647. 1234-1243. Gottesdienstmenäum für Oktober - November, Festmenäum für Dezember - August, zweites Viertel des 13. Jh. / erste Hälfte des 14. 
Jh. Altserbisch (Богдановић 1982: 49-50; Штављанин-Ђорђевић et al. 1986: 340-347)

$\mathrm{D}$

Народна библиотека Србије (Београд), Деч. (ursprünglich: Handschriftensammlung des Klosters „Visoki Dečani“" in Kosovo) Nr. 32. Gottesdienstmenäum für Juli - August, Ende 13. - Anfang 14. Jh. Altserbisch (Богдановић 1982: 56; Гроздановић-Пајић, Станковић 1995: 12)

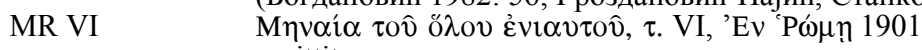

om omittit

ÖNB

Österreichische Nationalbibliothek (Wien)

S Государственный исторический музей (Москва), Син. 168. Gottesdienstmenäum für August, 12. Jh. Altrussisch. (Каталог 1984: 128-129)

Sin550 Sinai Katharinenkloster, Sin. gr. 550. Pandekten. 13. Jh. (Gardthausen 1886: 133; Clark 1952: 8)

Sin632 Sinai Katharinenkloster, Sin. gr. 632. Gottesdienstmenäum für August. 12. Jh. (Gardthausen 1886: 146; Clark 1952: 9)

Т Российский Государственный архив древних актов (Москва), ф. 381 (Тип.), Nr. 125. Gottesdienstmenäum für August. 11.-12. Jh. Altrussisch (Каталог 1984: 83-84)

SJS Slovník jazyka staroslověnského, t. I - IV, Praha 1958-1997

W33 Österreichische Nationalbibliothek (Wien), cod. Vind. theol. gr. 33. Gottesdienstmenäum für März - August. 13. Jh. (Hunger, Kresten 1976: 5764)

ГИМ Государственный исторический музей (Москва)

НБС Народна библиотека Србије (Београд)

РГАДА Российский государственный архив древних актов (Москва)

СлРЯ XI-XVII вв. Словарь русского языка XI-XVII вв., вып. 1 -27 -, Москва 1975

\section{L i t e r a t u r}

Beck 1959: H.-G. Beck, Kirche und theologische Literatur im Byzantinischen Reich (= Byzantinisches Handbuch im Rahmen des Handbuchs der Altertumwissenschaft, 2. Teil, 1. Bd.), München

Clark 1952: Checklist of Manuscripts in St. Catherine's Monastery, Mount Sinai, microfilmed for the Library of Congress, 1950. Prepared under the direction of K. W. Clark, Washington

Émerau 1923: C. Émerau, Hymnographi byzantini, Écho d'Orient 22, 12-25, 420-439

Follieri 1964: $\quad$ E. Follieri, Problemi di innographia bizantina, in: Actes du XII ${ }^{\mathrm{e}}$ congrès international d'études byzantines, t. II, Beograd, 311-325

Follieri 1962: $\quad$ H. Follieri, Initia Hymnorum Ecclesiae Graecae, vol. III, O- $\Sigma$ (= Studi e testi 213), Città del Vaticano

Follieri 1966: $\quad$ H. Follieri, Initia Hymnorum Ecclesiae Graecae, vol. V, pars prior, $\Phi-\Omega$ Hymnographi - Tabulae (= Studi e testi 215), Città del Vaticano

Gardthausen 1886: V. Gardthausen, Catalogus codicum graecorum sinaiticorum, Oxonii

Grumel 1950: V. Grumel, Léon de Chalcédoine et le canon de la fête du saint Mandylion, Analecta Bollandiana 68, 135-152

Hannick 1973: Ch. Hannick, Die Akrostichis in der kirchenslavischen liturgischen Dich-

Hannick 2004: $\quad$ Ch. Hannick, Zur Entwicklung der Forschungen zur byzantinischen Liturtung, Wiener Slavistisches Jahrbuch 18, 151-162 gie im 20. Jahrhundert, in: Triodion und Pentekostarion nach slavischen Handschriften des 11.-14. Jahrhunderts, Teil I: Vorfastenzeit, hrsg. von M. A. Momina, N. Trunte (= Abhandlungen der Nordrhein-Westfälischen Akademie der Wissenschaften, 110. Bd., H. Rothe (Hrsg.), Patristica Slavica, 11. Bd.), Paderborn - München - Wien - Zürich, 361-369

Hunger - Kresten 1976: H. Hunger, O. Kresten, Katalog der griechischen Handschriften der Österreichischen Nationalbibliothek. Teil 3/1. Codices theologici 1-100, Wien 
Krumbacher 1897: K. Krumbacher, Geschichte der byzantinischen Litteratur von Justinian bis zum Ende des Oströmischen Reiches (527-1453), 2. Aufl. bearb. unter Mitwirkung von A. Erhard, H. Gelzer, Vol. II, München (Nachdruck: New York, s. a.)

Krumbacher 1904: K. Krumbacher, Die Akrostichis in der griechischen Kirchenpoesie, in: Sitzungsberichte der philosophisch-philologischen und der historischen Klasse der K. B. Akademie der Wissenschaften zu München. Jahrgang 1903, München, 551-691

Lampe 1961: $\quad$ G. W. H. Lampe, A Patristic Greek Lexicon, Oxford (reprinted 1968, 1972)

Liddell - Scott - Jones 1996: A Greek-English Lexicon comp. by H. G. Liddell, R. Scott, rev. and augm. throughout by Sr. H. S. Jones ..., with a revised supplement, Oxford

Momina 1990: $\quad$ M. A. Momina, Zum Problem der Korrektur slavischer gottesdienstlicher hymnographischer Bücher in der Rus' des XI Jh., Zeitschrift für slavische Philologe 50/1, 16-49

Onasch 1981: $\quad$ K. Onasch, Kunst und Liturgie der Ostkirche in Stichworten unter Berücksichtigung der Alten Kirche, Wien - Köln - Graz

Plank 1996: $\quad$ P. Plank, Kanon in der Hymnodie, in: W. Kasper (Hrsg.), Lexikon für Theologie und Kirche, 5. Bd.: Hermeneutik bis Kirchengemeinschaft, Freiburg - Basel - Rom - Wien, 1184-1185

Plank - Lutzka 2006: Das byzantinische Eigengut der neuzeitlichen slavischen Menäen und seine griechischen Originale, II. Teilband: Incipitarium und Edition der Monate März bis August, erarb. von P. Plank, C. Lutzka, hrsg. von C. Hannick (= Abhandlungen der Nordrhein-Westfälischen Akademie der Wissenschaften, 112. Bd., H. Rothe (Hrsg.), Patristica Slavica, 12. Bd.), Paderborn

Rocchi 1883: Codices Cryptenses seu abbatiae Cryptae Ferratae in Tusculano digesti et illustrati cura et studio D. Antonii Rocci, Tusculani

Szövérffy 1979: A Guide to Byzantine Hymnography. A Classified Bibliography of Texts

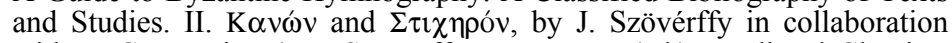
with E. C. Topping (= J. Szövérffy, F. Wagner (ed.), Medieval Classics: Texts and Studies, 12), Brookline (Mass.), Leyden

Totzke 1996: $\quad$ I. Totzke, Irmos, in: W. Kasper (Hrsg.), Lexikon für Theologie und Kirche, 5. Bd.: Hermeneutik bis Kirchengemeinschaft, Freiburg - Basel Rom - Wien, 600

Trapp 2005: Lexikon zur byzantinischen Gräzität, besonders des 9.-12. Jahrhunderts. 5. Faszikel $(\lambda-\pi \alpha \lambda \iota \alpha$ c $v \theta \rho \omega \pi \circ \varsigma)$, erstellt von E. Trapp unter Mitarbeit von S. Schönauer u. a. (= Veröffentlichungen der Kommission für Byzantinistik, hrsg. von O. Kresten und W. Seibt, Bd. VI/5), Wien

Varnalidis 1995: S. Varnalidis, Georgios, Metropolit v. Nikomedien, in: W. Kasper (Hrsg.), Lexikon für Theologie und Kirche, 4. Bd.: Franca bis Hermenegild, Freiburg - Basel - Rom - Wien, 484

Volk 1997: $\quad$ O. Volk, Klemens, hl., in: W. Kasper (Hrsg.), Lexikon für Theologie und Kirche, 6. Bd.: Kirchengeschichte bis Maximianos, Freiburg - Basel Rom - Wien, 128

Warland 1993: $\quad$ R. Warland, Acheiropoieta, in: W. Kasper (Hrsg.), Lexikon für Theologie und Kirche, 1. Bd.: A bis Barcelona, Freiburg - Basel - Rom - Wien, 112

Wellesz 1962: $\quad$ E. Wellesz, A History of Byzantine Music and Hymnography, $2^{\text {nd }}$ ed., revised and enlarged, Oxford

Weyh 1908: $\quad$ W. Weyh, Die Akrostichis in der byzantinischen Kanonesdichtung, Byzantinische Zeitschrift 17, 1-69

Богдановић 1982: Д. Богдановић, Инвентар ћирилских рукописа у Југославији (X XVII века) (= Српска академија наука и уметности. Зборник за историју, језик и књижевност српског народа. Отд. I, Књ. XXXI), Београд 
Гроздановић-Пајић - Станковић 1995: М. Гроздановић-Пајић, Р. Станковић, Рукописне књиге манастира Високи Дечани. Књига друга. Водени знаки и датирање (= Народна библиотека Србије. Опис јужнословенских ћирилских рукописа, т. IV), Београд

Добрев 2002: И. Добрев, Каноните за св. Иван Рилски от Георги Скилица, Palaeobulgarica $=$ Старобългаристика 27/3, 3-12

Каталог 1984: Сводный каталог славяно-русских рукописных книг, хранящихся в СССР. XI-XIII вв., Москва

Князевская et al. 1988: О. А. Князевская, Н. С. Коваль, О. Е. Кошелева, Л. В. Мошкова, Каталог славяно-русских рукописных книг XI-XIV вв., хранящихся в ЦГАДА СССР, часть первая, Москва

Кривко 2005: $\quad$ Р. Н. Кривко, Уточнение датировки древнейшего списка славянской служебной минеи за август, in: Линвгистическая герменевтика I, Москва, 90-110

Крысько 2005: Ильина книга. Рукопись РГАДА, Тип. 131. Лингвистическое издание, подготовка греческого текста, комментарии, словоуказатели В. Б. Крысько, Москва

Крысько 2005a: В. Б. Крысько, О греческих источниках и реконструкции первоначального текста древнейшей службы Кириллу Философу, Palaeobulgarica = Старобългаристика 29/4, 30-63

Мурьянов 1982: М. Ф. Мурьянов, Славистические маргиналии к книге грузинского византолога, in: М. Ф. Мурьянов, Гимнография Киевской Руси, Москва, 2003, 391-402

Попов 1998: $\quad$ Г. Попов, Канон за Рождество Христово от Константин Преславски, Palaeobulgarica = Старобългаристика 22/4, 3-26

Попов 2003: Г. Попов, Акростих в гимнографическом творчестве учеников Кирилла и Мефодия, in: K. Stantchev, M. Yovcheva (ed.), La poesia liturgica slava antica. XIII Congresso Internazionale degli Slavisti (Lubiana, 1521 Agosto 2003). Blocco tematico $n^{\circ} 14$. Relazioni, Roma, Sofia, 30-55

Сергій 1901: Полный м'ссяцесловъ Востока, т. II, Өвлтой Востокъ, д. Б. Архіепископа Сергія, изданіе второе исправленное и много восполненное, Владимиръ (репринт: Москва 1997)

Суботин-Голубовић 1987: Т. Суботин-Голубовић, Одвојене службе светима у грчким минејима XI века, Археографски прилози 9, 317-320

Суботин-Голубовић 1992: Т. Суботин-Голубовић, Две службе св. Јоакиму Осоговском, Археографски прилози 14, 105-131

Суботин-Голубовић 1995: Т. Суботин-Голубовић, Упоредно проучавање структуре српских и византијских минеја старијег периода, in: П. Ивић (ур.), Проучавање средњовековних јужнословенских рукописа, Београд, 439446

Темчин 2007: С. Темчин, О происхождении древнейшего канона Константину-Кириллу Философу, in: H. Rothe - D. Christians (Hrsg.), Liturgische Hymnen nach byzantinischem Ritus bei den Slaven in ältester Zeit, Beiträge einer internationalen Tagung, Bonn 7.-10. Juni 2005 (= Abhandlungen der Nordrhein-Westfälischen Akademie der Wissenschaften, 117 Bd., H. Rothe (Hrsg), Patristica Slavica, 15 Bd.), Paderborn - München - Wien Zürich, 328-339

Штављанин-Ђорђевић et al. 1986: Љ. Штављанин-Ђорђевић, М. Гроздановић-Пајић, Л. Цернић, Опис ћирилских рукописа Народне библиотеке Србије (= Народна библиотека Србије. Опис јужнословенских ћирилских рукописа, т. II), Београд

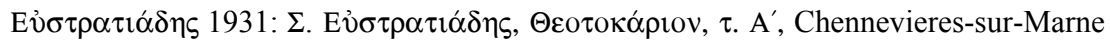

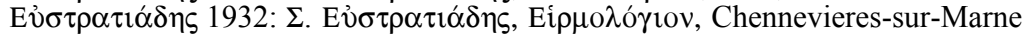

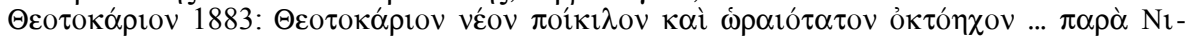

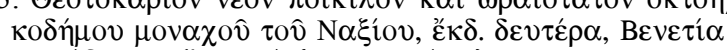

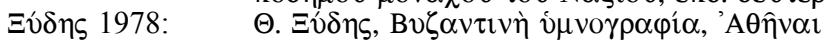




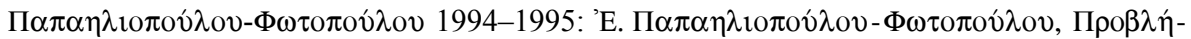

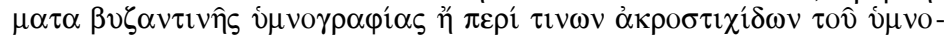

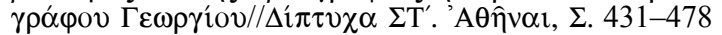

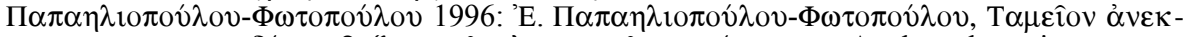

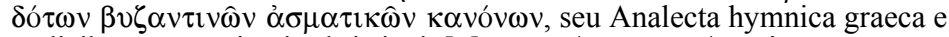

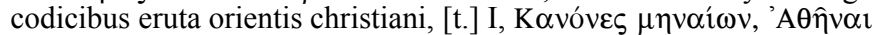

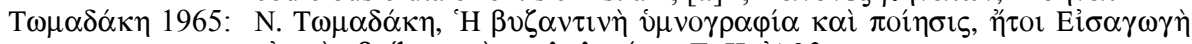

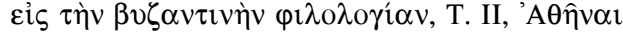

Roman Krivko

Институт русского языка

им. В. В. Виноградова РАН, Волхонка 18/2,

RU-119019 Москва, rkrivko@yandex.ru 